\title{
Man/Hombre/Homme: Respuestas a las necesidades de la salud reproductiva masculina en América Latina
}

Debbie Rogow

Judith Bruce

Population Council

Ann Leonard

Follow this and additional works at: https://knowledgecommons.popcouncil.org/departments_sbsr-pgy

Part of the Family, Life Course, and Society Commons, Gender and Sexuality Commons, International Public Health Commons, and the Public Health Education and Promotion Commons How does access to this work benefit you? Let us know!

\section{Recommended Citation}

Rogow, Debbie, Judith Bruce, and Ann Leonard. 1991. "Man/Hombre/Homme: Respuestas a las necesidades de la salud reproductiva masculina en América Latina," Quality/Calidad/Qualité no. 2. New York: Population Council. 
Man/Hombre/Homme:

Respuestas a las Necesidades

de la Salud Reproduction

Masculina en América lbadina

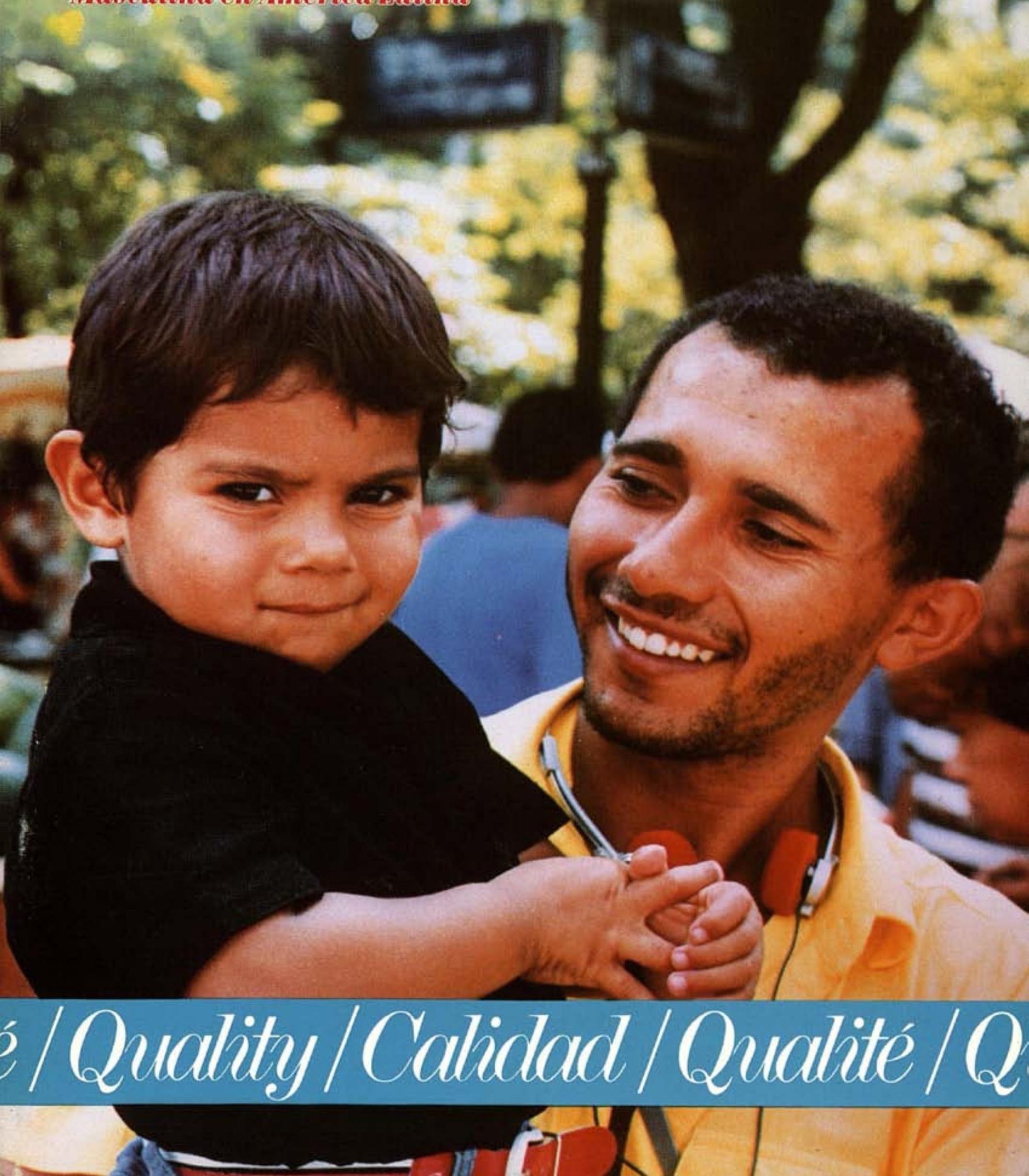


Quality/Calidad/Qualité es una publicación del Population Council que documenta ejemplos de programas de planificación familiar y salud reproductiva que proveen un nivel de calidad de atención estraordinariamente alto. Esta serie forma parte del Programa Robert H. Ebert sobre Temas Críticos en Salud Reproductiva y Población, un programa del Council que busca mejorar y ampliar el alcance y la calidad de la atención en salud reproductiva a través de iniciativas científicas y prácticas. La base filosófica del programa, y de esta serie, es el derecho fundamental de las mujeres y sus parejas al trato respetuoso, la información, las opciones y el seguimiento por parte de los proveedores de atención en salud reproductiva. Los folletos reflejan uno de los cuatro impulsos principales del programa: aumentar la calidad de los programas de planificación familiar.

Los proyectos que se incluyen en Quality/Calidad/Qualité son seleccionados por un Comité Asesor de individuos que representan una amplia gama de experiencia en el ámbito de la salud reproductiva, y que están comprometidos a mejorar la calidad de atención. Los proyectos se eligen por estar logrando importantes avances en por lo menos uno de los siguientes aspectos: ampliar la gama de opciones de métodos y tecnologías anticonceptivas disponibles; proporcionar la información que las clientes necesitan para hacer elecciones informadas y para controlar mejor su salud reproductiva; mejorar la calidad del trato entre proveedor y cliente, promoviendo la continuación del contacto entre ambos; iniciar proyectos innovadores para aumentar la capacidad administrativa y ampliar el nivel de capacitación de los proveedores de servicios a todo nivel; extender la gama de servicios e información más allá de lo que convencionalmente se define como "planificación familiar"; y alcanzar, con los servicios de salud reproductiva, a grupos que generalmente no los reciben.

Ninguno de los proyectos incluidos en la serie se está presentando como un modelo para la replicación. Se ofrecen más bien como un ejemplo singularmente creativo de valores, objetivos y aplicación de ideas. Estas son "experiencias de aprendizaje" que ilustran la necesidad de mantener una actitud autocrítica para anticipar las necesidades de las clientes y para encontrar medios económicos de satisfacerlas. Esta actitud reflexiva se manifiesta en la voluntad de responder a los cambios en las necesidades de las clientes y en las transformaciones económicas y sociales en general. Esperamos que la documentación de las decisiones críticas que estos programas han tenido que hacer ayudará a reforzar, en términos prácticos, la evidencia de que la satisfacción del individuo con los servicios de salud reproductiva está fuertemente ligada al logro de objetivos más amplios en salud y población.

La publicación de esta edición de Quality/ Calidad/Qualité en español ha sido posible por el apoyo brindado por la Fundación Prospect Hill.
Las declaraciones y opiniones expresadas en esta publicación son la responsabilidad exclusiva del autor y no de ninguna organización que provea apoyo para Quality/ Calidad/Qualité.

La edición en inglés se publicó en 1990.

Edición en español No. 21991 ISSN 0-87834-057-2 Copyright (C) The Population Council 1991 


\title{
Man/Hombre/Homme: Respuestas a las Necesidades de la Salud Reproductiva Masculina en América Latina
}

\author{
Por Debbie Rogow \\ Introducción y conclusión de Judith Bruce y Ann Leonard
}

\section{Introducción}

¿Salud reproductiva masculina? No se ha dedicado mucho tiempo, pensamiento o recursos a definir su significado, y menos a proveer servicios centrados en el hombre. Hasta hace poco, el énfasis de la salud reproductiva y la planificación familiar han sido las mujeres, una elección obvia, como indica IPPF, por “...la muy real amenaza que significan los excesivos embarazos para la salud de la mujer, la estrecha relación entre planificación familiar y la emancipación femenina, y la decisión política y práctica en muchos países en vías de desarrollo de ofrecer servicios de planificación familiar a través de los centros de salud materno-infantil".'

Pero a partir de los años 80 , cuando los programas comenzaron a buscar estrategias que les permitieran alcanzar un más amplio espectro de usuarios por medio de la expansión de su constelación de servicios, las necesidades de la salud reproductiva masculina empezaron a recibir alguna, aunque bien limitada, atención. En 1981, la Conferencia Internacional de Planificación Familiar en los Ochenta (Jakarta, Indonesia) afirmó que los hombres tienen los mismos derechos reproductivos que las mujeres, es decir, el derecho a controlar sus cuerpos. La conferencia además notó que los servicios existentes no reflejaban dichos derechos, y recomendó que, como prioridad para la década, se incluyeran más programas para hombres.

Sin embargo, la implementación de tales iniciativas ha sido entorpecida por una inadecuada definición de "salud reproductiva masculina". Germain ha definido los programas de salud reproductiva femenina como "los que tienen como objetivos básicos la elección reproductiva y la reducción de la incidencia de enfermedades y mortalidad debido a la función reproductiva femenina" mientras al mismo tiempo reconoce la interrelación entre la salud de la madre y la supervivencia de la criatura. ${ }^{2}$ Lo que ha ayudado a formular tal definición ha sido una mejor comprensión de la secuencia de las preocupaciones de las mujeres sobre su salud a lo largo de sus vidas reproductivas. Para los hombres, no existe tal clara secuencia de inquietudes.

Hasta ahora, no se conoce mucho sobre cómo los hombres ven su función reproductiva y su vida sexual, y hay muy poco en vías de investigación o en programas experimentales que podrían ayudarnos a aprender más. La escasa información existente sugiere que los hombres están altamente motivados con respecto al funcionamiento sexual efectivo y satisfactorio, $y$ al tratamiento de enfermedades transmitidas sexualmente. Sabemos menos aún acerca de lo que mueve a los hombres a preocuparse por un embarazo no deseado. Como el embarazo es una condición experimentada por otra persona-por definición, un hombre nunca estará embarazado-las motivaciones del hombre para usar anticonceptivos eficazmente en su relación de pareja radican en preocupaciones ajenas a su propia salud reproductiva, tales como su relación emocional con su pareja sexual, su preocupación por la salud de ella, y su deseo de aceptar o evitar la responsabilidad de tener hijos. 
La desafortunada combinación de actitudes masculinas y animadversión de los proveedores, ha dado como resultado que los hombres sean un grupo desatendido y pobremente preparado para planificación familiar y atención médica reproductiva. Frecuentemente, el orgullo masculino hace a los hombres reacios a admitir su ignorancia sobre reproducción, sexualidad y anticoncepción; y se ha determinado que debido a que los servicios de planificación familiar dirigen sus esfuerzos a alcanzar y servir mujeres, los hombres pocas veces aprenden de profesionales de la salud sobre la anticoncepción. Aunque existe un poco de información para los usuarios masculinos, hay aún menos materiales educativos para profesionales de la salud que traten sobre temas de la salud reproductiva masculina. ${ }^{3}$

Los intentos de alcanzar a los hombres deben tener en cuenta la renuencia de muchos de ellos a buscar abiertamente información o servicios; la importancia de la relación, en la mente masculina, entre funcionamiento sexual apropiado y la fertilidad; y la orientación de muchos profesionales de salud hacia la atención médica de las mujeres. En algunos casos, hay una historia que superar. Por ejemplo, en algunos países en vías de desarrollo se han promovido las vasectomías a través de opresivas campañas que incluían el pago de incentivos. Debido a que la calidad de esos servicios de vasectomía ha sido a veces dudosa, y a que esas campañas han sido incapaces de realizar seguimiento de casos, y menos de responder a las necesidades masculinas relacionadas con la salud reproductiva, en algunos lugares han dejado un legado de disgusto y desconfianza. Y aunque hace mucho tiempo que se ha dispuesto de condones en las clínicas de planificación familiar, pocos hombres se acercan a pedirlos. La pequeña cantidad que se usa es porque se los llevan mujeres clientes o el personal masculino de la clínica. Los hombres que usan condones prefieren el anonimato de la farmacia o de un supermercado, un hecho que ha sido explotado exitosamente por un creciente número de programas de mercadeo social.

Una definición de largo alcance de la salud reproductiva masculina debería ir más allá del reconocimiento del derecho de los hombres a controlar sus cuerpos y permanecer libres de enfermedades, para incluir alguna noción de cooperación entre hombres y mujeres en términos de sexualidad, la anticoncepción y el evitar la transmisión de enfermedades. El incremento de la anticoncepción masculina podría ayudar a balancear el riesgo reproductivo, porque, aunque sólo las mujeres sobrellevan los riesgos del nacimiento del nin̄o, ambas personas en la pareja pueden compartir los riesgos y cargas de la práctica anticonceptiva. Las enfermedades de transmisión sexual y la aparición del SIDA, nos recuerdan las consecuencias de una falta de cooperación entre hombres y mujeres, y que el único medio efectivo de reducir la diseminación de enfermedades sexuales, aparte de la monogamia o la abstinencia, es que el hombre use condones.

Incluso si el creciente énfasis en la responsabilidad compartida entre hombres y mujeres no resulta en un incremento significativo en el uso de anticonceptivos masculinos, aún podría hacer una contribución importante en cuanto a promover una mayor comunicación en la pareja sobre su salud reproductiva y sus preocupaciones sobre la fertilidad. Esto podría, en las palabras de la IPPF, incluir a los hombres "en la planificación y el cuidado de los niños. Sin eso... las mujeres continuarán teniendo niños no deseados y buscarán ayuda anticonceptiva en secreto. También estarán más expuestas a abandonar el esfuerzo cuando ocurren problemas anticonceptivos, porque no tendrán la cooperación y ayuda de sus maridos y compañeros".

Aunque admitimos que todavía hay mucho que no sabemos, el conocimiento actual afirma que los hombres valoran la privacidad, la conveniencia, la información, los profesionales amables, y la atención de necesidades de salud reproductiva más allá de la anticoncepción. Por eso son de considerable interés los dos programas presentados en este número de Quality/Calidad/Qualité, PRO-PATER en Brasil y la Clínica para el Hombre, de PROFAMILIA, en Colombia. Aunque la vasectomía es el punto principal de ambos programas, cada uno de ellos ofrece mucho más. Ambos programas han tenido que lidiar con asuntos complejos relacionados con la provisión de cuidado médico en temas tales como infertilidad, disfunción sexual, y enfermedades de transmisión sexual, así como con el sostenimiento de sus programas. Su experiencia sugiere que, aunque las necesidades de la salud reproductiva masculina pueden ser diferentes de aquellas articuladas para las mujeres, los hombres están intensamente interesados y dispuestos a usar servicios que sean de fácil accesibilidad y alta calidad. 


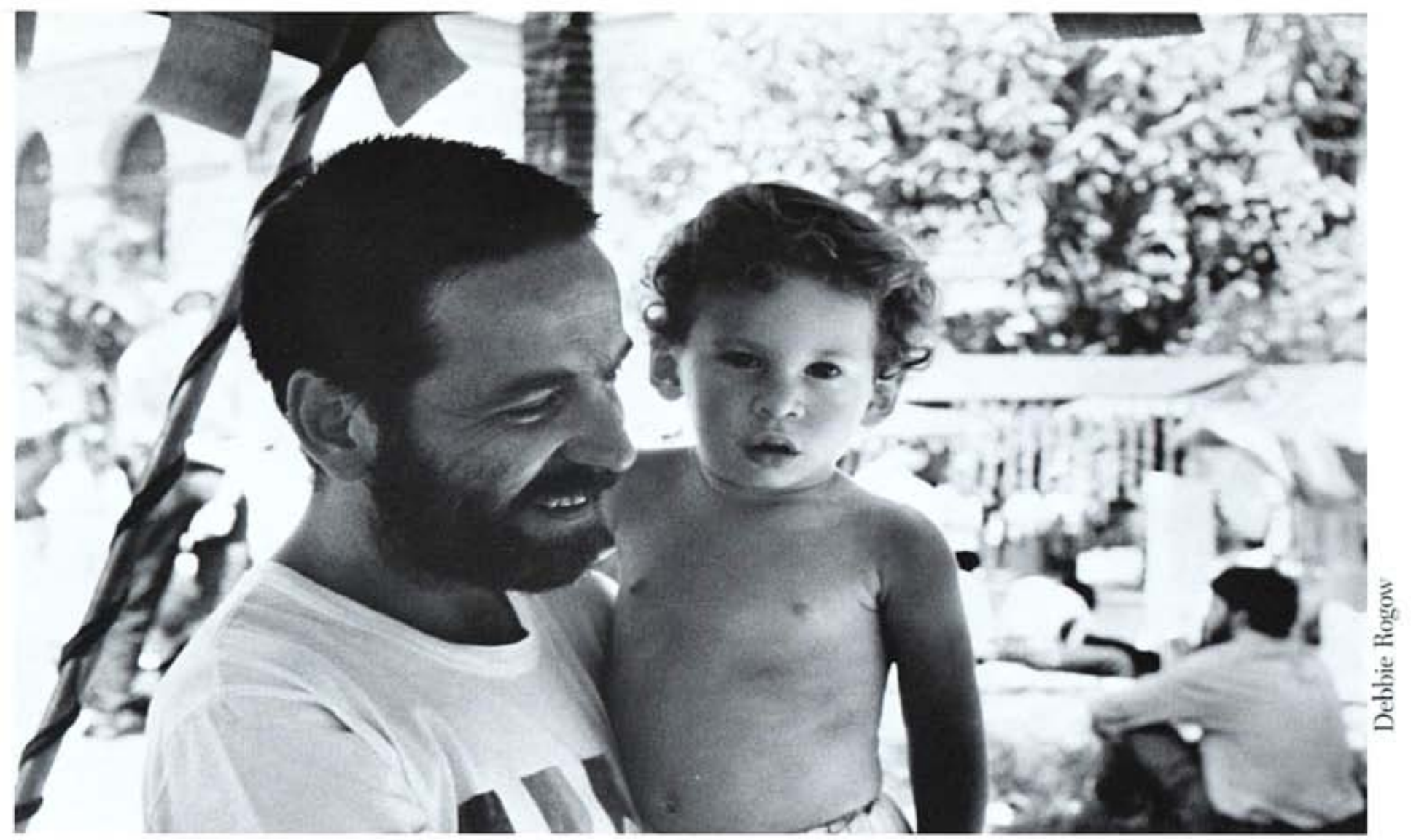

\section{Antecedentes}

El término "programa de vasectomías" puede convocar negativas imágenes de campamentos improvisados $\mathrm{y}$ de candidatos interesados primordialmente en el pago de un incentivo. En los partidarios del concepto de decisión informada, causa cierto rechazo la idea de programas de planificación familiar que ofrecen la esterilización como única opción anticonceptiva.

Aunque en algunos países la vasectomía es relativamente popular (del 5 al 10 por ciento en los Estados Unidos, Canadá y algunas partes de Asia), en ningún lugar es más popular que la esterilización femenina. En Brasil, por ejemplo, donde el uso generalizado de anticonceptivos es alto (66 por ciento) y el índice de esterilización femenina llega a ser el 27 por ciento entre mujeres de 15 a 49 años en relación de pareja, la vasectomía representa menos del uno por ciento de los casos. ${ }^{5}$

De modo que si hasta ahora los servicios de vasectomía no han jugado un papel estelar en la planificación familiar, también es cierto que los programas comprensivos de salud reproductiva masculina no han sido parte del cuadro. Cierto es que desde mediados de los años 70 algunas pequeñas "clínicas masculinas" han estado funcionando en los Estados Unidos, pero generalmente se ocupan de adolescentes. Es realmente raro encontrar en un país en vías de desarrollo un programa que se ocupe de infertilidad, consejería en sexualidad y esterilización, pensado por y para hombres.

Esta edición de Quality/Calidad/Qualité trata de responder al interrogante de cómo los servicios de salud reproductiva pueden entender y enfocar mejor los intereses masculinos, por medio del estudio de la experiencia de PRO-PATER, en San Pablo, Brasil, y más brevemente, la experiencia complementaria de la Clínica para el Hombre, de PROFAMILIA, en Colombia. El primero es un programa de salud reproductiva "para hombres solamente"; el segundo, es un ejemplo de cómo pueden crearse clínicas para hombres anexas a un exitoso programa de larga trayectoria dirigido primariamente a las mujeres.

\section{PRO-PATER: de clínica de vasectomías a programa de salud reproductiva para hombres}

PRO-PATER (Promoción de la Paternidad Responsable) es una clínica de salud reproductiva masculina ubicada en San Pablo, Brasil. 
Concebida inicialmente para "crear un espacio donde los hombres pudieran participar más plenamente en la planificación familiar", PROPATER estableció una clínica de vasectomías en 1981, como respuesta a preocupaciones sobre la predominancia de la esterilización femenina en el Brasil. En ese tiempo, la vasectomía era prácticamente desconocida y virtualmente no practicada en el país.

El servicio de vasectomías se ha basado en una filosofía de decisión informada y calidad de servicio, ejemplificados por una consejería cuidadosa, períodos obligatorios de espera, excelente servicio clínico y riguroso seguimiento. Este enfoque no sólo refleja la filosofía del equipo de PRO-PATER, sino también una buena dosis de sagacidad política. En años recientes ha habido en el Brasil un considerable debate sobre la situación legal de la esterilización, y sobre cómo ésta se podía interpretar a la luz del aparato legal existente. Ahora, la nueva constitución del país da a las personas mayores de 21 años, en su sano juicio, el derecho de decidir el número de niños que desean, y de tomar las medidas necesarias para prevenir embarazos no deseados.

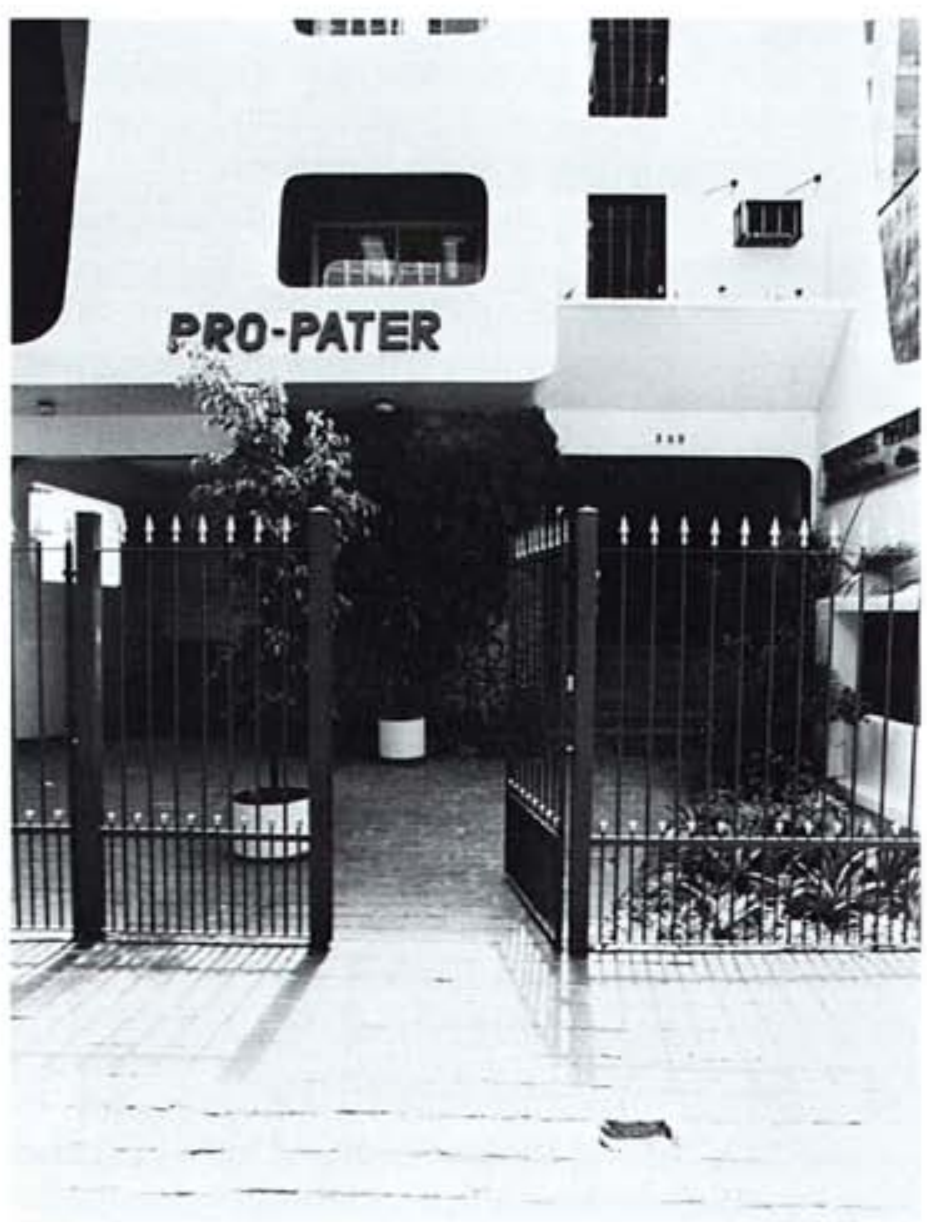

Con el paso del tiempo PRO-PATER ha expandido gradualmente sus servicios para reflejar un enfoque más comprensivo de la salud reproductiva masculina. Dice la co-fundadora y actual administradora de la clínica, Bernadette Martín de Castro:

"Quisimos crear un lugar donde los hombres pudieran hablar con mayor libertad, recibir educación y tener la oportunidad de ejercitar su responsabilidad por la reproducción de la pareja. Muchos urólogos no tratan asuntos reproductivos, y pocos ginecólogos comprenden las preocupaciones masculinas. Los hombres necesitan su propio espacio físico. En ese sentido, podríamos decir que nuestro proyecto es a la vez 'macho' y 'anti-macho"".

PRO-PATER ofrece consejería sexual individual, así como tratamiento de factores orgánicos relacionados con disfunción sexual. También se ofrecen tratamientos de casos de infertilidad que, obviamente, incluyen al hombre y su pareja. Y por haber sido una de las muy pocas clínicas brasileñas que practicaban vasectomías, PRO-PATER se ha convertido rápidamente en un importante centro de investigación y entrenamiento sobre la vasectomía.

\section{El programa de vasectomías}

Aún hoy, la práctica de vasectomías continúa siendo la actividad principal de PROPATER. En 1989 se entrevistaron 7.028 nuevos candidatos para la operación, lo que representa el 97 por ciento del total de nuevos casos de la clínica. En el mismo año, se practicaron 5.242 vasectomías. El cliente promedio a quien se le practica la operación tiene entre 30 y 40 años de edad, es padre de dos o tres niños, y tiene educación secundaria; está más acostumbrado que otros hombres brasileños a usar condones. Por lo demás, la clientela es heterogénea, y representa todos los sectores de la sociedad brasileña.

Un cliente potencial para una vasectomía debe tener primero una entrevista con un consejero. Su pareja puede acompañarle en esta entrevista. Cuando visité la clínica, alrededor de un 25 por ciento de los clientes habían traído con ellos a sus esposas. El consejero hace la historia clínica del hombre, tratando de ver sus motivos para considerar la posibilidad de la vasectomía, explica los beneficios y riesgos de 


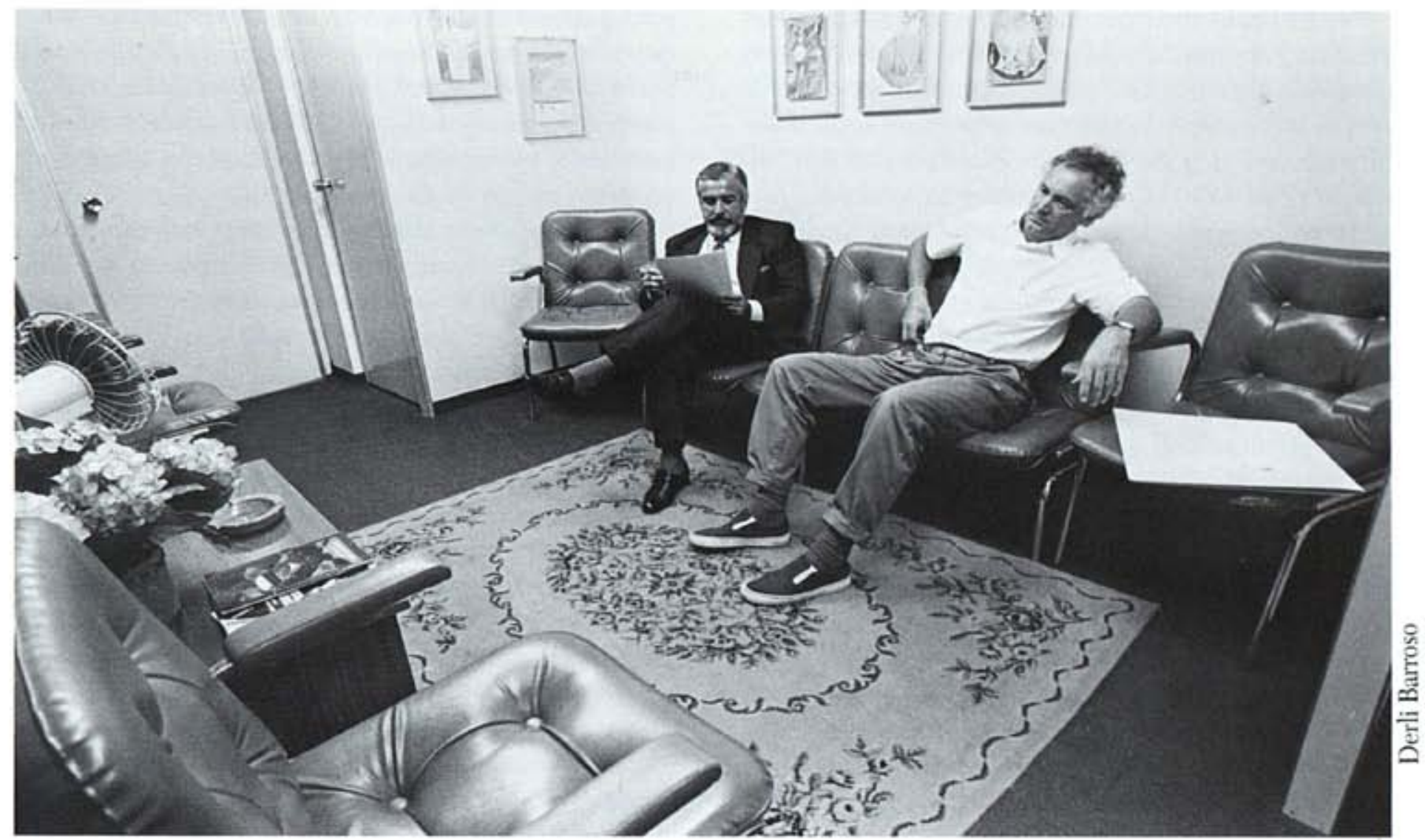

los otros métodos (los de uso femenino y los condones), y averigua si el cliente está interesado en alguno de ellos.

Los siguientes casos están basados en entrevistas observadas por la autora:

João tiene 29 años, y está casado desde hace 5. Tanto él como su esposa Jurema son graduados de la universidad y son propietarios de su casa. Tienen dos niños pequeños; el menor tiene sólo seis meses de edad. João es supervisor de una planta farmacéutica. Se enteró de las vasectomías por un cartel de PRO-PATER que vio en la planta. Después de hablar sobre el tema con el médico de la compañía, habló sobre su decisión con su esposa. João está pensando en la vasectomía por varias razones:

"En primer lugar, el ciclo menstrual de Jurema es muy irregular, y nunca sabemos si es que se le ha retrasado o es que está embarazada. Para regular el ciclo ha estado tomando Clomid [un medicamento que estimula la ovulación, frecuentemente usado para tratamientos de esterilidad], y anticonceptivos orales, pero no ha habido ningún resultado. Estamos contentos con tener dos niños, pero nos preocupa que en algún momento no podamos, no sólo alimentarlos, sino también educarlos".
João y Jurema han tratado de usar la espuma anticonceptiva, pero no les gusta. Ambos sienten que el ligamiento de trompas o el aborto conllevan muchos riesgos. Han escuchado malas historias sobre dispositivos intrauterinos-amigas que resultaron embarazadas-al igual que relatos de que han sido causa de esterilidad y muerte.

João dice que tiene un tío que se hizo una vasectomía y parece satisfecho, pero no le ha hablado todavia sobre sus planes. Si lo ha hecho con su jefe, que es también su amigo, y éste le ha dicho: "Yo no sé; en mi tiempo esa operación no existía. No sé si yo me la hubiera hecho". Según Joāo, su plan es continuar conversando sobre el asunto con Jurema. Tiene un 90 por ciento de seguridad de que va a seguir adelante con su decisión de hacerse la vasectomía. Ha hecho una cita para volver:

Claudio tiene también 29 años, y ha estado casado desde los 22. El y su esposa Laisa han tenido cuatro niños, uno de los cuales murió a los cuatro meses de edad. Laisa está embarazada de 8 meses. Claudio es portero de una gran residencia. Laisa le ayuda en su trabajo. Claudio gana 40 dólares por mes (menos que el salario mínimo) y recibe la vivienda y algo de comida. 
Claudio dice que no quiere más hijos por razones económicas. La crisis en el Brasil le hace dificil mantener a sus niños, especialmente ahora con el advenimiento del nuevo bebé. Se enteró de la vasectomía y de la existencia de PRO-PATER en un centro de salud del gobierno, a donde fue para recibir consejo sobre planificación familiar. Laisa ha tomado la píldora, pero según Claudio, la pone nerviosa y deprimida.

Cuando la consejera describe otros métodos anticonceptivos disponibles, esta es la respuesta de Claudio: "No nos interesa el dispositivo intrauterino, porque tiene muchos riesgos. He tratado de usar condones, pero no me gustan. Nuestro segundo hijo nació porque nos falló el método del ritmo. Ultimamente hemos estado usando el método de retirarme antes de eyacular. Hasta ahora no ha fallado, pero..."

Claudio añade: "Mi esposa ha tenido problemas de salud, operaciones, y tiene alta presión. No ha podido esterilizarse por causa de esos problemas. Por esa razón fui al centro de salud; quería preguntar qué tenían para los hombres, $y$ ellos me enviaron aquî". Está un poco nervioso. Explica: "nadie en mi familia se lo ha hecho". Después de que la consejera explica el procedimiento, Claudio pregunta si podría "afectar el sexo, incluso en el futuro". La consejera dice que no, y le sugiere a Claudio que vuelva a hablar del tema con el médico. El vuelve a preguntar: "¿No podría volverme impotente?" Ella explica que la operación en sí misma no tiene ningún efecto en absoluto sobre la función sexual. Lo que puede causar impotencia son factores psicológicos. Si una persona tiene serias preocupaciones de indole sexual, es posible que tenga problemas después de hacerse la vasectomía.

En PRO-PATER, cada cliente pasa por un examen médico, después de la sesión con el consejero. Luego del examen, si el cliente y el equipo clínico están de acuerdo en que es un buen candidato para la vasectomía, se le pide firmar un formulario de consentimiento. Aunque durante la sesión de consejo se ha hablado sobre la comunicación con su esposa, el consentimiento de ella no es necesario para el procedimiento. Se le pide entonces al cliente que espere por un período breve (por lo general una semana) antes de hacer la vasectomía. Esto le permite considerar cuidadosamente la decisión.

Por supuesto, la mayoría de los clientes recibirán una aprobación para la vasectomía, pero PRO-PATER estudia seriamente si el cliente es un

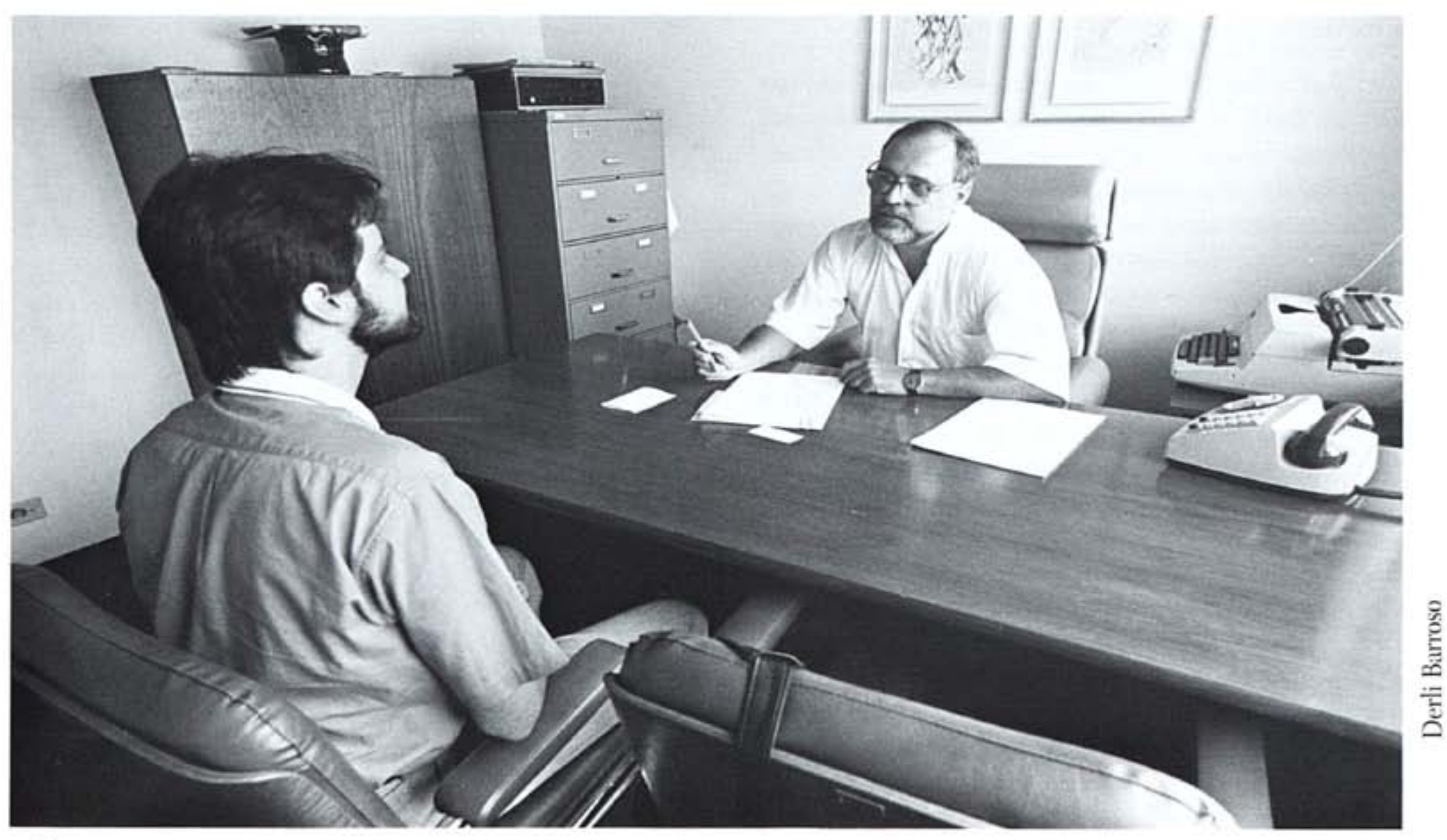


buen candidato para un procedimiento permanente. El 21,5 por ciento de los entrevistados son rechazados o se les sugiere una postergación. La razón más frecuente es que la esposa del cliente está embarazada o que acaban de tener un bebé. Otras razones para la negativa pueden ser que el hombre esté eligiendo la vasectomía para resolver un problema marital o sexual; que sea psicológicamente inestable o menor de 25 años de edad; que tenga menos de dos niños; o que se pueda encontrar un método anticonceptivo que responda mejor a las necesidades de la pareja. El tiempo que llevan casados influye también en la negativa o postergación. No existen consideraciones económicas: nadie es dejado de lado porque no tenga dinero para pagar.

En el caso de João, la consejera le pidió que esperase-hasta que el bebé de seis meses fuera algo mayor y menos vulnerable, y que pensara qué ocurriría con su decisión si algo le pasaba a los niños o a su esposa (con la posibilidad de un nuevo matrimonio). Seis meses después, cuando el bebé cumplió un año, Joāo volvió a PRO-PATER para hacerse la vasectomía. Por la misma razón, la consejera le dijo a Claudio que esperara a que el bebé, aún no nacido, tuviera por lo menos 6 meses de edad.

Tal prudencia es importante. Es bastante común el arrepentimiento después de una esterilización cuya decisión se tomó en forma apresurada. En un reciente estudio hecho con mujeres del estado de San Pablo que habían sido esterilizadas en los dos años anteriores, el 25 por ciento respondió que si pudieran hacer retroceder el tiempo, no hubieran tomado la misma decisión. ${ }^{6}$ En PRO-PATER, en nueve años y con más de 28.000 procedimientos, apenas ha habido 17 pedidos de reversión del procedimiento de clientes cuyas vasectomías se ejecutaron allí. La clínica también practica el procedimiento de reversión, pero mayormente para hombres cuyas vasectomías fueron hechas en otro lado. La reversión es costosa, y no siempre tiene éxito. Por eso el estudio previo de los candidatos es claramente una mejor opción. No sólo se benefician los clientes, sino también PRO-PATER, cuyo prestigio profesional se ha incrementado por operar una clínica que ha practicado miles de procedimientos que por mucho tiempo estuvieron en una zona gris para la legislación brasileña.

Después de la vasectomía, el cliente recibe instrucciones para cuidado posterior, y se arregla una cita para dos meses después. El cliente sabe que si tiene problemas o dudas puede volver a la clínica antes de esa fecha y que en la próxima visita deberá proveer una muestra de semen para que sea analizado.

Aunque se requieren generalmente 20 eyaculaciones para "limpiar" el sistema de todos los espermatozoides, algunos hombres no lo consiguen en ese período, y se les pide que den otra muestra de semen después de otras 10 eyaculaciones. Cuando un cliente tiene todavía espermatozoides vivos después de tres análisis consecutivos de semen, se da por sentado que ha ocurrido una recanalización espontánea, y se sugiere una nueva operación, esta vez gratuita. Desde 1981, en sólo el 1,05 por ciento de las vasectomías ha ocurrido recanalización espontánea.

Una revisión comparativa muestra cuán a conciencia encara PRO-PATER el seguimiento de sus clientes. Muchos programas de vasectomía no ven nunca más a sus clientes después del procedimiento, y en programas en países en vías de desarrollo se consideran altos los índices de seguimiento del 50 o el 60 por ciento. En parte porque también mantiene contacto con sus clientes por medio del correo, PRO-PATER ha logrado un índice de seguimiento post-vasectomías del 76,4 por ciento.

Cada cliente que entra en PRO-PATER cuesta en promedio US\$69,54. Si al cliente se le practica una vasectomía, el costo se incrementa en otros US\$ 40,62: un total de US\$ 110,16 por cliente operado. La clínica recibe 2.500 dólares mensuales de la Association for Voluntary Surgical Contraception (AVSC) para ayudar a sufragar los costos quirúrgicos. El resto del costo se cubre con lo que paga el cliente (PRO-PATER establece sus honorarios proporcionalmente al ingreso del cliente), o con los ingresos por otros servicios de la clínica. La organización no recibe ningún reembolso por los clientes que han recibido consejo pero no han sido esterilizados.

\section{Tratamiento de la disfunción sexual}

En muchos aspectos, PRO-PATER está todavía desarrollando su modelo para los servicios de tratamiento de la disfunción sexual. Esta sección comenzó unos pocos años atrás, cuando Marcos Paulo P. de Castro, médico y co-fundador de la clínica, se vio en la necesidad de responder a gran cantidad de inquietudes rela- 


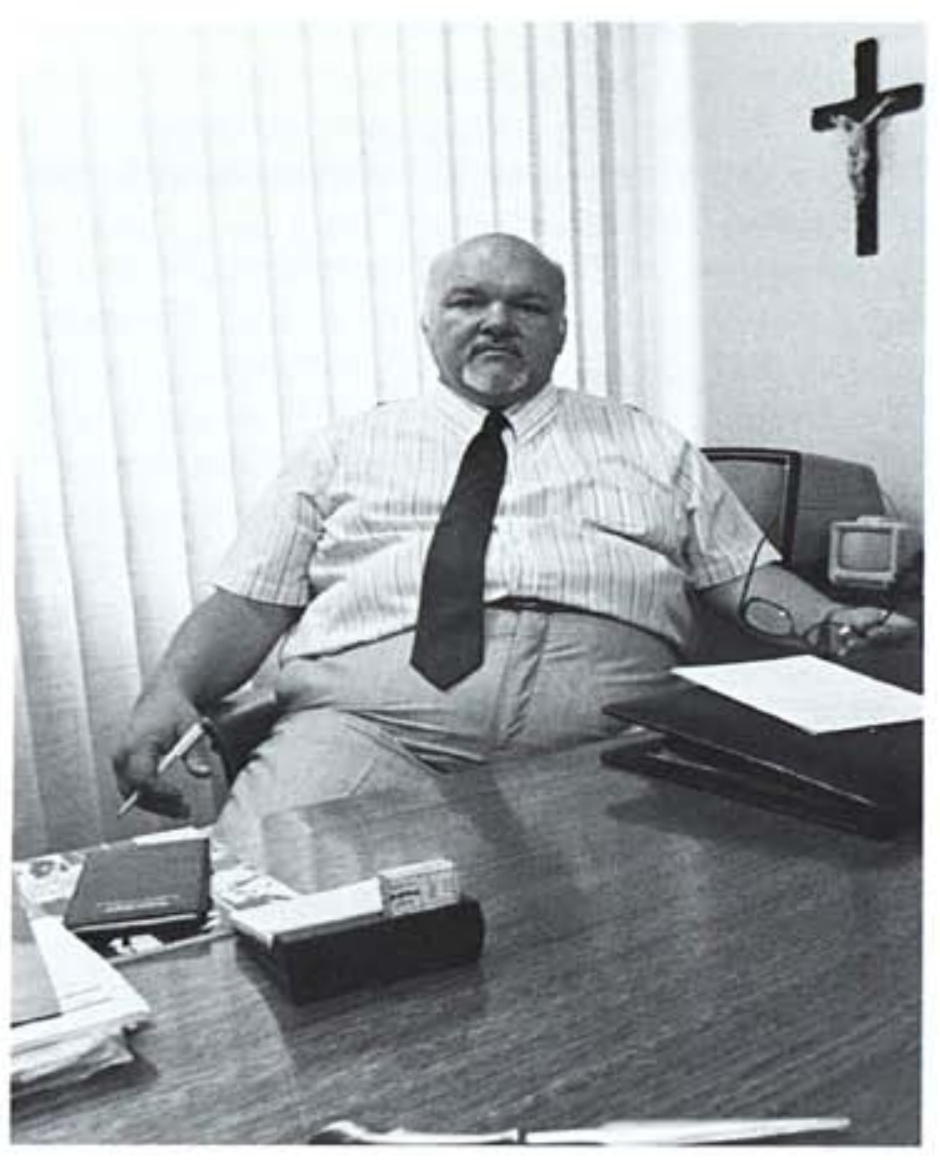

cionadas con la sexualidad, presentadas por los clientes de vasectomías y de urología.

En el principio, la clínica sometía a los clientes con dichos problemas a un examen físico a fondo, y cuando era necesario, los derivaba a un psicólogo externo. En 1986 se agregó un psicólogo al equipo, para proveer directamente tal servicio. Comenta el Dr. de Castro: "Casi el 100 por ciento de los casos tienen un componente psicológico. Usamos el modelo P-LI-SS-IT para determinar las necesidades del cliente". El modelo PLISSIT es un procedimiento de cuatro pasos sucesivos para responder a las preocupaciones psicológicas sobre la sexualidad.?

Según Roberto Veras, el psicólogo de PRO-PATER, el grupo mayor es el de los que tienen dificultades en conseguir o mantener una erección. El grupo siguiente, por orden de importancia, es el de los que sufren eyaculación prematura o retardada. Veras ve a los clientes sólo después de que han sido examinados por un médico. Aunque muchos de estos hombres no tienen realmente problemas físicos, Veras dice que al principio se resisten a identificar sus preocupaciones sexuales como de origen psicológico; es más fácil pensar que algo anda mal en su cuerpo. Tales clientes son inicialmente reacios a la intervención del psicólogo, y esperan recibir medicamentos o ser sometidos a un procedimiento quirúrgico que elimine el problema.

El examen médico prepara el camino para explorar las dimensiones psicológicas del problema. Esto es también un ejemplo del concepto integrado que tiene PRO-PATER de la salud reproductiva masculina. Dice Veras: "cuando veo a un cliente, por medio de su historia clínica y una consulta con el equipo, ya tengo una visión completa de él como persona".

Generalmente, Veras trata con su cliente sólo cuatro veces. Por esta razón, se reúne privadamente con él, en lugar de con él y su pareja, o separadamente con su pareja (los clientes que requieren una terapia más larga son derivados a otros servicios externos apropiados). La técnica general de Veras es dar al cliente elementos con los cuales analizar su vida como una totalidad, y su sexualidad como parte de ella. Por ejemplo, un cliente joven, llamado Jorge, se quejó de eyaculación prematura. "Estaba ansioso. Durante la primera entrevista, me di cuenta que Jorge no tenía tiempo para parar, para comer, para relajarse. Estaba constantemente corriendo. De modo que tratamos de ver cómo eso estaba afectando su sexualidad. En esencia, también estaba corriendo hacia la cama".

Sigue diciendo Veras: "Para controlar la eyaculación prematura, a veces usamos técnicas conductistas como la de Masters y Johnson de apretar el glande para controlar la eyaculación. Algunos clientes aceptan tales técnicas. Pero como fueron desarrolladas en los Estados Unidos, y esta es una sociedad latina, muchos hombres, como Jorge, no se sienten a gusto poniéndolas en práctica, ya sea por medio de masturbación o pidiendo la ayuda de la pareja. Además, aunque estas técnicas conductistas funcionen, frecuentemente aparecen otros problemas, tales como la impotencia. Así que, en el caso de Jorge, trabajamos sobre qué es lo que lo hacía correr y en qué formas podía controlar su vida y desacelerarse".

Veras describe cómo, además de ser incapaces de analizar su vida, muchos de los hombres que ve tienen una opinión muy pobre de su masculinidad y no están preparados para hablar sobre sus sentimientos, y menos aún para mencionar sus preocupaciones sobre la sexualidad. "Como resultado, en general se sienten muy solos. A veces, enseñar técnicas de 
comunicación puede ser de ayuda. Tuve un caso de recién casados, Maristela y Eugenio. Maristela, que llegó virgen al matrimonio, sentía dolor al ser penetrada durante el acto sexual. Su ginecólogo le enseñó a hacer algunos ejercicios, que sirvieron de ayuda. Tan pronto como ella se sintió 'mejor' Eugenio comenzó a eyacular prematuramente. Estaba muy ansioso cuando vino a la clínica. Dijo que se sentía igualmente ansioso cada vez que se iba a la cama. Maristela era una persona más calma.

“Tan pronto como Eugenio comenzó a ver que su estado nervioso permeaba su vida entera, empezó a darse cuenta de que no era su sexualidad lo que fallaba. Maristela y Eugenio aprendieron a decirse lo que les gustaba y no les gustaba del otro, y de sus vidas en general. Su vida sexual se hizo menos ansiosa a medida que su nueva vida juntos estableció zonas de comodidad y comunicación".

A veces, solamente educar ayuda en gran manera. Recientemente un cliente se quejó de que su esposa era frígida. Además de explorar lo que estaba pasando en su relación con su esposa y cómo se sentía él en cuanto al sexo, Veras se dio cuenta de que el cliente conocía muy poco sobre sexualidad, y le hablo sobre la función del clítoris. El cliente, inmediatamente relajado, dijo: "no sabía que podía tocarla allí para hacerla excitar". Progreso.

La clínica ha visto también un creciente número de casos de disfunción sexual que son de aparente u obvio origen orgánico. Algunos casos de severa impotencia se tratan con hormonas. Ha habido también casos de diabéticos con daño vascular permanente y parapléjicos que han requerido prótesis de pene. Después de que en un programa de la televisión local PRO-PATER exhibió un filme sobre prótesis de pene, se cuadruplicó el número de hombres que vinieron a la clínica para tratamiento de disfunción sexual.

Los honorarios por este tipo de tratamiento varían, pero en general, este componente proporciona ingresos adicionales a la clínica. Ofreciendo el servicio una mañana por semana, hasta fines de 1989 PRO-PATER había tratado a más de 300 clientes.

\section{Tratamientos de infertilidad}

Los tratamientos de infertilidad en PROPATER no son en sí un modelo único. Comienzan con estudios básicos tales como análisis de semen, lectura de temperatura basal corporal y exámenes postcoitales. Lo que es único es que

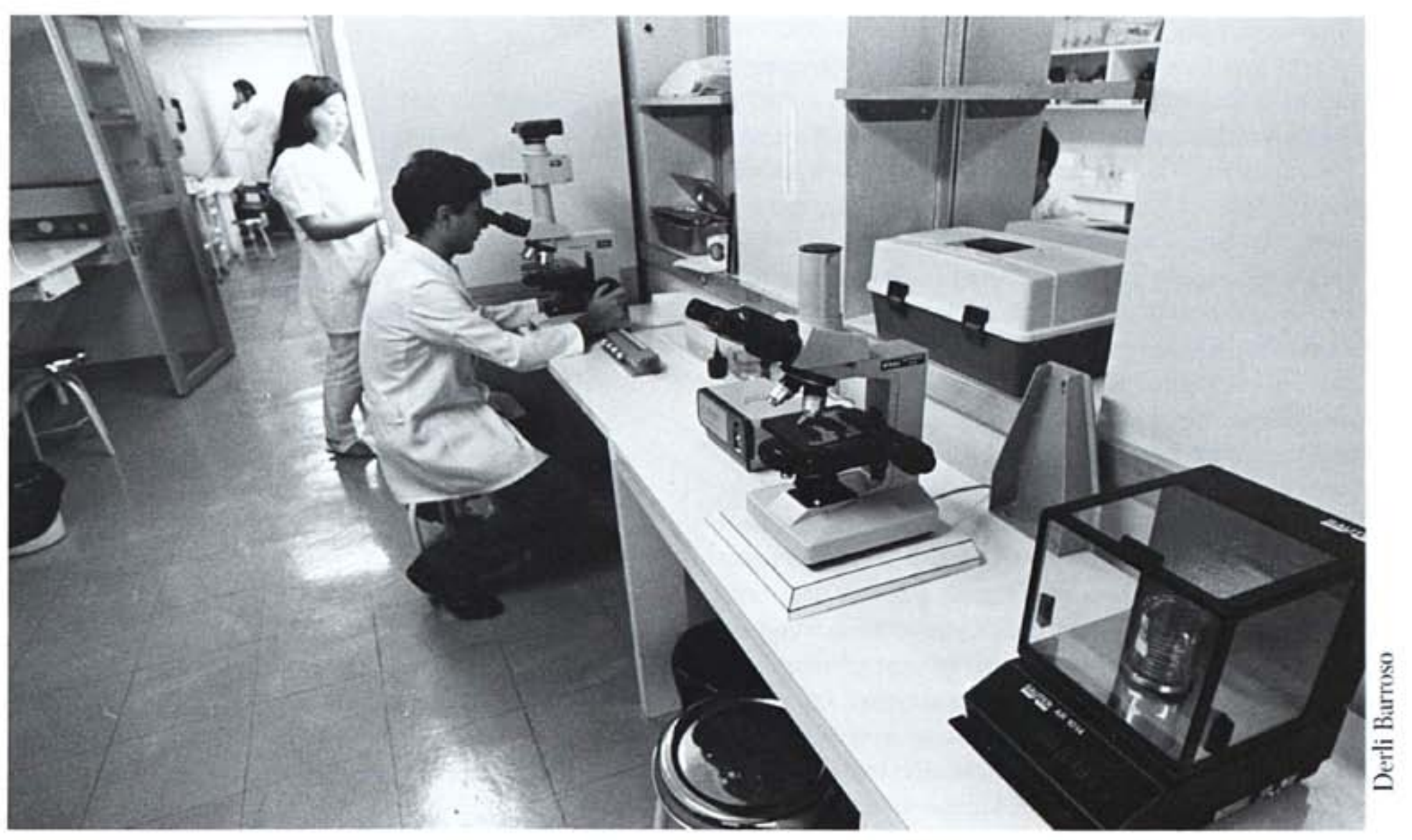


estos servicios se ofrecen en una clínica para hombres. En un ambiente así, se le da gran atención a los aspectos fisiológicos y psicológicos de la infertilidad masculina. Aunque se ve a ambos miembros de la pareja, el hombre no queda relegado, como a veces pasa cuando la pareja va a un consultorio privado o a una clínica que sirve primariamente a mujeres.

Aunque el número de casos de infertilidad tratados en PRO-PATER es pequeño (menos de 50 por año), la clínica espera que este componente continúe creciendo, y que, como el programa de disfunción sexual, pueda subvencionar el programa de vasectomías, que es deficitario. Para este servicio también los honorarios son proporcionales al ingreso del cliente.

\section{Investigación y entrenamiento}

Además de proveer atención médica de gran calidad, un elemento que da carácter distintivo a PRO-PATER es su rol como institución de investigación y tratamiento. La clínica mantiene registros completos de sus clientes, de modo que en cualquier momento la computadora puede brindar información estadística. Además, se han hecho varios proyectos de investigación relacionados con su campo de acción.

Con el apoyo de Family Health International, PRO-PATER realizó y publicó un estudio de prácticas médicas relacionadas con la anticoncepción. ${ }^{*}$ La encuesta, hecha con 660 médicos del Estado de San Pablo, reveló que casi la mitad no había recibido entrenamiento médico en planificación familiar, y que tenían tendencia a recomendar los métodos que conocían mejor. La actitud de los médicos en cuanto a la esterilización femenina y masculina fue muy positiva, sin reflejar preferencias sobre el ligamiento de trompas o la vasectomía.

Un segundo estudio de PRO-PATER fue un proyecto de investigación operacional subvencionado por el proyecto INOPAL del Population Council. Desarrollados por una firma publicitaria local, se publicaron a toda página avisos sobre vasectomías en varias revistas de gran circulación entre la clase media. La campaña fue exitosa: el número de nuevos clientes que solicitaban vasectomías creció de 300 a 500 por mes. Sin embargo, el número de vasectomías aumentó solamente de 250 a 350 por mes.
Aunque el flujo de clientes aumentó en gran cantidad, la clínica debió aconsejar también a una mayor cantidad de individuos a los cuales al final no se les practicó vasectomías. El incremento en visitas iniciales y número de vasectomías duró casi un año. ${ }^{9}$

PRO-PATER sirve también como centro de entrenamiento para médicos de todo el Brasil y de otros países latinoamericanos. Se ofrecen regularmente cursos de entrenamiento en vasectomías, y la organización es claramente la fuente principal de entrenamiento en Brasil. Una vez al año, se pide a todos los participantes de los cursos de entrenamiento que contesten por correo un cuestionario. PRO-PATER también hace seguimiento de los profesionales entrenados para determinar el número de procedimientos que practican, las características de su ejercicio de la profesión, etc.

A pesar del cuidadoso banco de información que PRO-PATER mantiene, la coordinadora Bernadette Martín de Castro dice que si algún error se ha cometido, es en no haber mantenido registros suficientemente detallados para propósitos de investigación clínica. El equipo de PRO-PATER es conocido por el cuidado con que realizan sus investigaciones, $y$ es evidente que disfrutan en relacionar su expe-
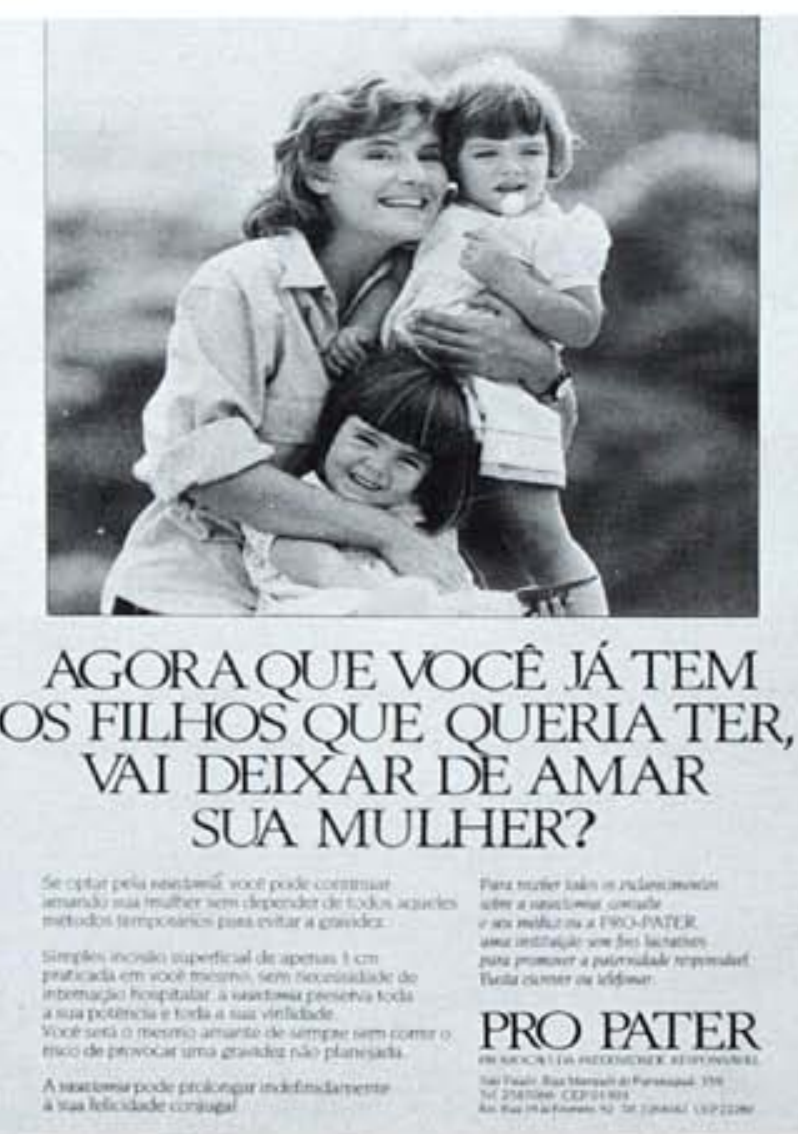

OS FILHOS QUE QUERIA TER, VAI DEIXAR DE AMAR SUA MULHER?

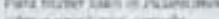

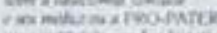

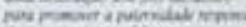
PRO PATER

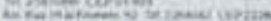




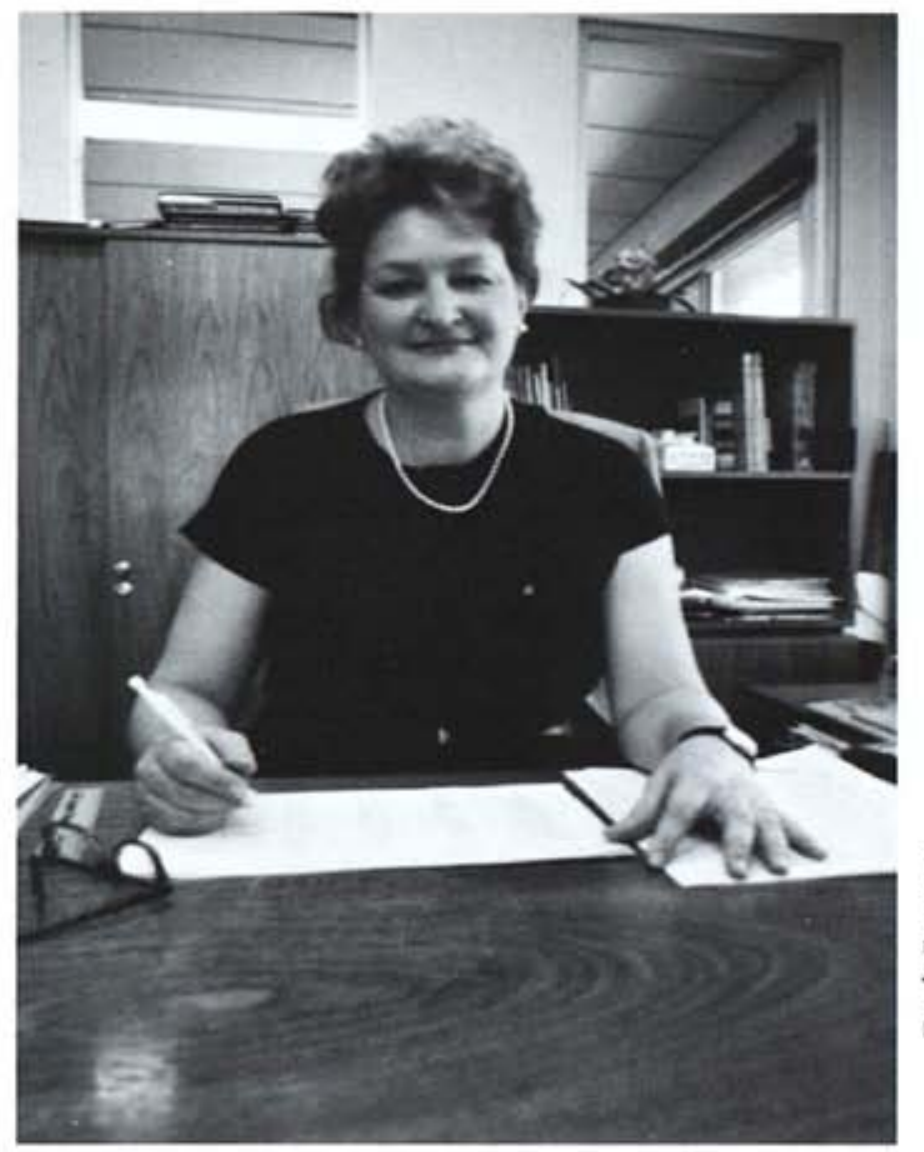

riencia clínica con la investigación, para ofrecer mayores conocimientos al campo de la planificación familiar.

\section{Expansión}

Después de un estudio realizado para definir de qué areas de la zona metropolitana de San Pablo sus clientes provienen, en mayo de 1988 PRO-PATER abrió una clínica sucursal en el distrito industrial de Belém, para estar en un lugar más cercano al área donde trabajan la mayoría de los clientes, y así reducir el número de horas en que estos necesitarían estar ausentes de sus trabajos. El mismo equipo médico de la clínica principal también ofrece sus servicios en Belém, alternándose entre los dos sitios. Los empleados administrativos de Belém son o personas que han trabajado en la clínica principal o que han recibido un completo entrenamiento en el lugar:

\section{PRO-PATER se autoanaliza}

Posiblemente el aspecto más importante de cómo PRO-PATER se ve a sí mismo es su misión como una agencia de planificación familiar. En un país donde dos métodos son los que predominan, PRO-PATER desea ampliar las posibilidades de elección ofreciendo otro que había sido prácticamente desconocido para la población. La píldora y la esterilización femenina abarcan el 60 por ciento de los métodos anticonceptivos usados en Brasil. Ya que el ligamiento de las trompas no es una operación fácil de obtener, generalmente se lo realiza en ocasión de una operación cesárea, por lo cual hay un índice de cesáreas del 40 al 60 por ciento. Como los riesgos médicos de la cesárea y el ligamiento de trompas son mucho mayores que los de la vasectomía, el que las parejas hagan mayor uso de este método para no tener más niños tiene también una buena dosis de sentido común. Los profesionales de PROPATER explican que aunque ellos quisieran ver que la vasectomía tuviera un rol más grande en la planificación familiar, su interés es en incrementar la capacidad de elegir entre métodos disponibles, no controlar la población o reducir el índice nacional de natalidad.

Aparentemente, PRO-PATER tiene un sentido muy claro de qué es y qué no es. Un elemento con que la organización define calidad es la provisión del tratamiento más "profesional" posible, sin relación con la capacidad del cliente para pagar o no. El edificio de la clínica de PRO-PATER es hermoso, identificado en el exterior con un cartel de letras visibles y elegantes. Plantas, muebles cómodos y revistas adornan la sala de espera. Todas las entrevistas se realizan en pequeñas oficinas que ofrecen absoluta privacía. El laboratorio es inmaculado y bien equipado. Incluso João, que viene de un trasfondo de media clase, me dijo que él esperaba un edificio más pequen̄o, "más discreto," algo así como una casa. Se sintió agradablemente sorprendido cuando llegó a PRO-PATER.

La estrategia de mercado de PRO-PATER está relacionada con su cuidadosamente protegida imagen profesional. Mucha de la publicidad se hace a través de programas educativos en fábricas. Se hacen un promedio de 25 programas por año, para grupos de 20 a 60 trabajadores. En esas oportunidades se toca el tema de la salud reproductiva y se habla sobre todos los métodos anticonceptivos. PRO-PATER tiene relaciones cordiales con varias fábricas, y generalmente la iniciativa del programa viene de parte de la compañía, sin que PRO-PATER necesite pedir que se le invite. 


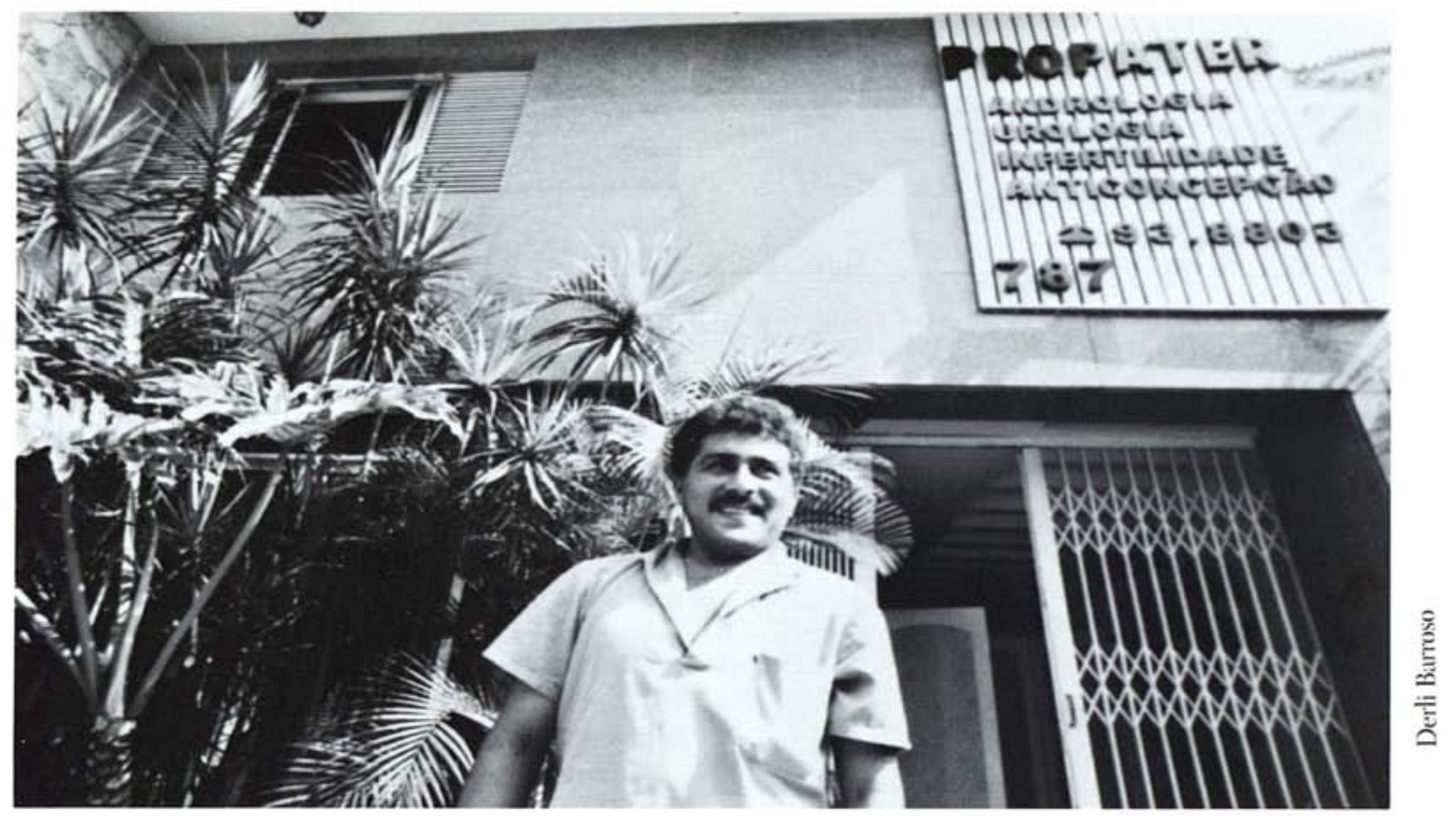

Hace algunos años, reconociendo que PRO-PATER se mueve en una zona políticamente sensitiva, el Dr. Marcos de Castro tomó la iniciativa de invitar a una reunión a varios líderes políticos y judiciales del Brasil para clarificar la legalidad de la vasectomía bajo las leyes brasileñas. El Dr. de Castro es también un activo miembro de la Asociación Brasileña de Entidades de Planificación Familiar (ABEPF). Ambas actividades han fortalecido políticamente la situación de PRO-PATER y de la vasectomía, haciéndolos menos vulnerables de lo que hubieran sido si la organización no hubiera establecido esas importantes relaciones. Más allá de todo, lo que ha protegido a PRO-PATER de la crítica sobre la naturaleza de sus actividades es su trayectoria de calidad en la atención.

PRO-PATER evalúa el éxito de su trabajo con vasectomías en base a la alta calidad de sus servicios técnicos y de consejería, y según la cambiante prevalencia de la vasectomía en San Pablo. Su nivel técnico puede medirse por el bajo índice de complicaciones y fallas; evalúan su consejería por la satisfacción del cliente al tiempo de su primera visita, dos meses después de la vasectomía (cuando los clientes vuelven a la clínica para el seguimiento y el análisis de la esperma), y por la ínfima cantidad de pedidos de reversión del procedimiento. Desde que PRO-PATER comenzó su actividad en San Pablo, el índice de vasectomías aumentó de 0,2 por ciento en 1981 a 2 por ciento en 1986 y al 5,7 por ciento en 1990 .

Uno de los desafios constantes que afronta el programa es el de mantenerse económicamente solvente, y al mismo tiempo cobrarle al cliente según sus ingresos. La situación ha empeorado en los años recientes debido a la crisis económica en el Brasil: el alquiler que PRO-PATER paga se cuadruplicó en un mes, y los salarios han aumentado a razón de un 20 por ciento mensual, en tanto que la capacidad de pago de los clientes no se ha mantenido a la altura del aumento de los costos.

Una de las razones para la estabilidad e identidad del equipo PRO-PATER viene de que saben lo que NO son. Aunque es difícil imaginarse una clínica de salud reproductiva masculina que no reparta condones, PROPATER ha decidido esa política por varias razones. Aunque el equipo aconseja a la pareja usar condones durante el período post-vasectomía (si es que no están usando otro método) y también se incluye información sobre condones en sus sesiones de consejería sobre anticoncep- 
ción, PRO-PATER nunca provee condones a los que están interesados en usarlos como métodos de planificación familiar, ni tampoco a los clientes a quienes se les ha practicado la vasectomía. Bernadette de Castro explica que la clínica ha tenido problemas en el pasado para obtener condones, y que no tiene los fondos necesarios para proveerlos gratuitamente. Pero incluso teniendo los recursos para hacerlo, la organización teme que muchas personas de bajos recursos podrían pedir los condones para después revenderlos en la calle. Y la idea de tener una licencia para vender condones en las instalaciones de la clínica, según el personal, sería demasiado "comercial". PRO-PATER tampoco distribuye condones en la comunidad, incluso aunque el personal sabe que la distribución de condones es más eficaz cuando se hace en forma comunitaria. Su preocupación es que colaborar en proyectos callejeros con otras organizaciones podría dañar la imagen profesional que tanto han trabajado para desarrollar y mantener.

Por la misma razón, aunque PRO-PATER trata clientes con enfermedades de transmisión sexual (con excepción de SIDA), no hace publicidad de esos servicios porque en San Pablo, las clínicas que hacen publicidad de tratamientos de enfermedades sexuales tienen en general mala reputación. A los clientes que piden análisis determinantes de infección con el virus del SIDA se los deriva a hospitales del gobierno.

Al concluirse mi visita, le pregunté a varios miembros del equipo de PRO-PATER cómo ven el futuro. Una posibilidad que están considerando es la formación de grupos de educación para adolescentes varones, con énfasis en control de la natalidad y sexualidad. Otra posibilidad es el desarrollo de un sistema de licencias para expandir el modelo de PROPATER. Explica el doctor de Castro: "Podríamos dar entrenamiento y asistencia técnica en los campos de sexualidad e infertilidad. Las otras organizaciones podrían usar, junto con su nombre, la leyenda 'afiliada a PRO-PATER: A cambio, deberían pagar una cuota como miembros, lo que daría a PRO-PATER un ingreso adicional". Y por supuesto, en los planes para el futuro siempre están incluidos nuevos proyectos de investigación.

\section{Cómo otros ven a PRO-PATER}

PRO-PATER es ampliamente respetada en el ambiente de la planificación familiar en el Brasil. Hablé acerca de PRO-PATER con direc-

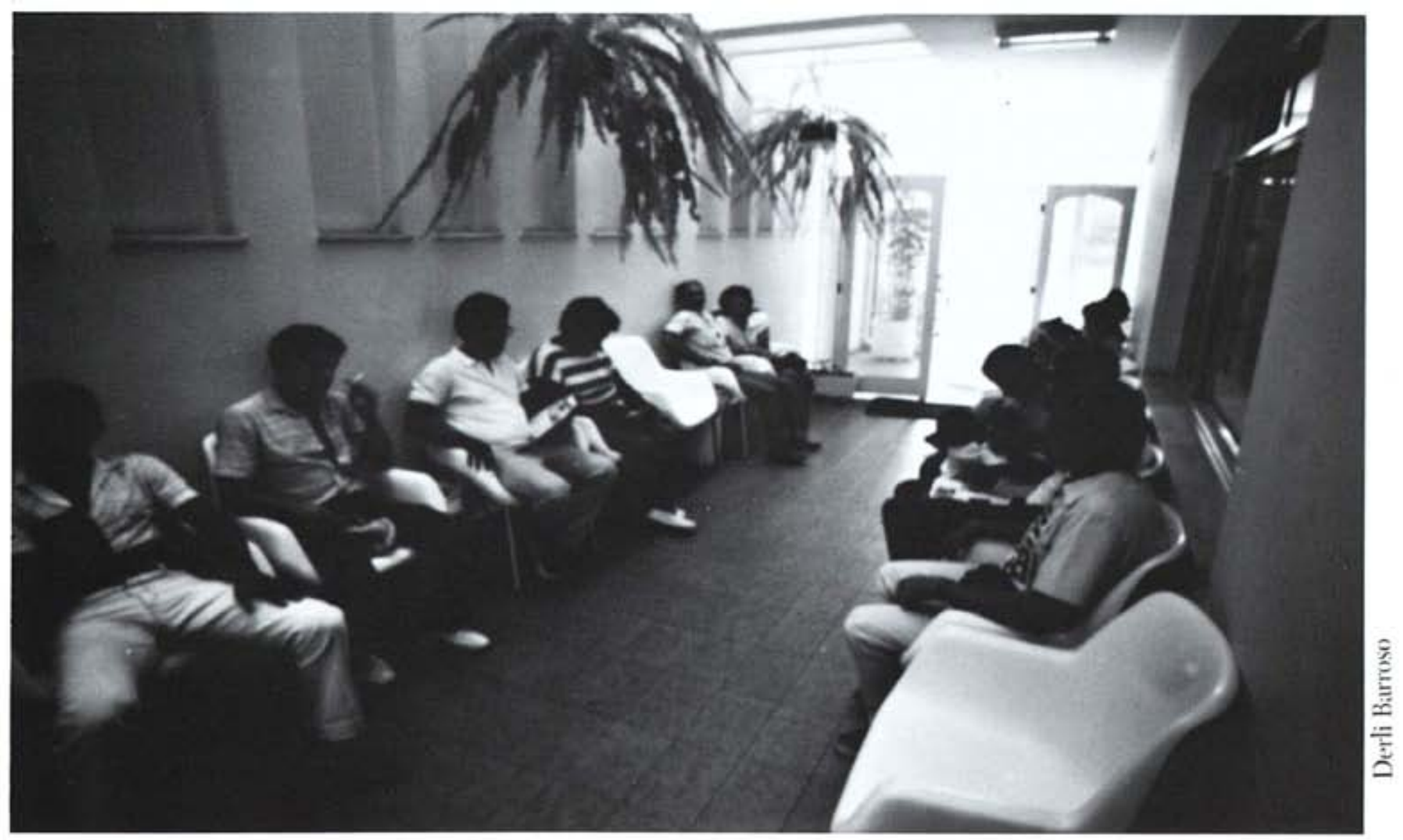




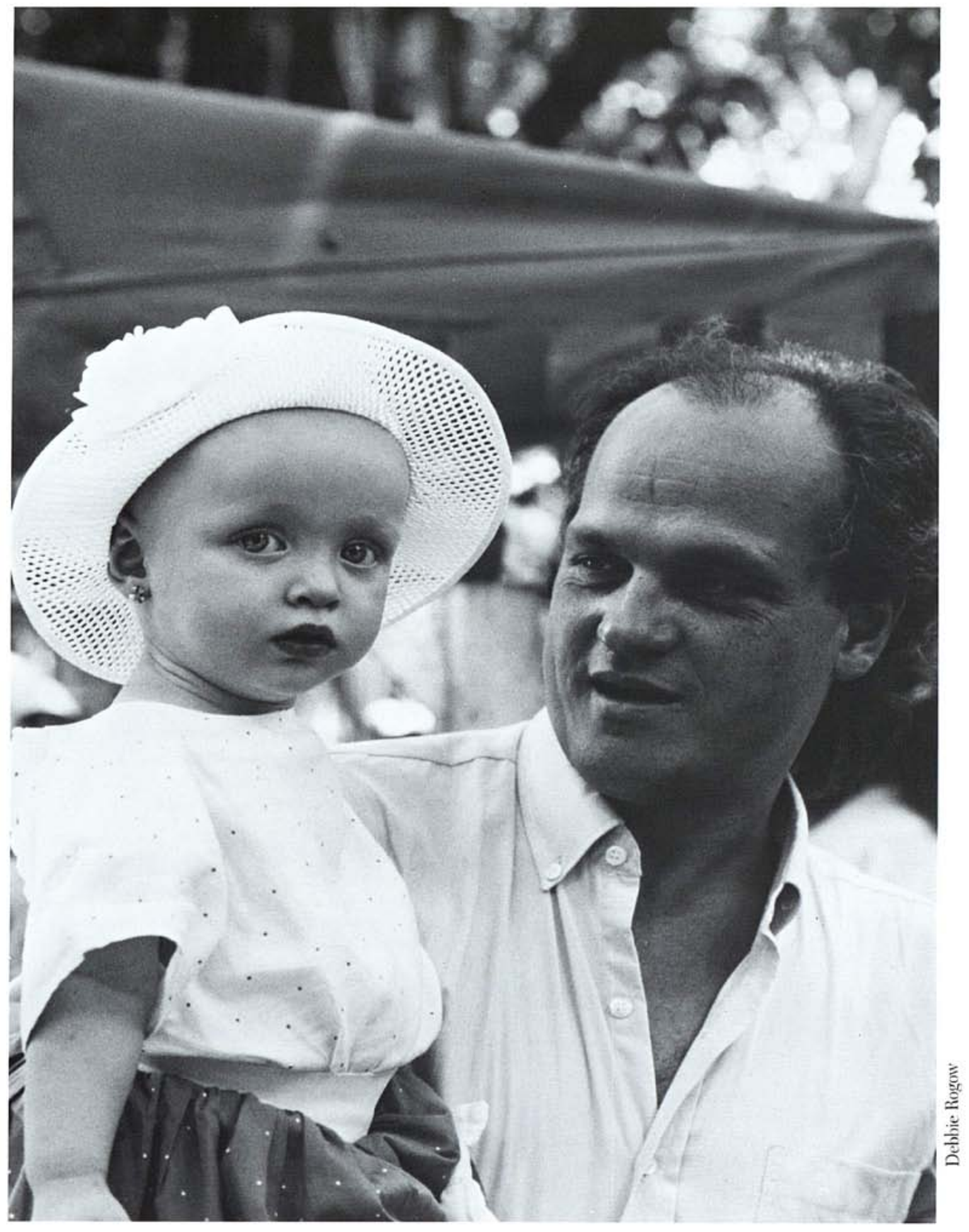


tivos de varias clínicas de planificación familiar que han recibido asistencia internacional, y que son activos en ABEPF, tales como Lia Kropsch del Centro de Investigaciones de Asistencia Integrada a la Mujer y a la Infancia (CPAIMC) y el doctor Milton Nakamura del Centro de Planificación Familiar. Ambos consideran a PROPATER un verdadero líder en el campo de vasectomías, y no creen que un servicio para hombres sea una amenaza a los programas femeninos de planificación familiar o para la asistencia económica que reciben.

El movimiento de salud de la mujer en el Brasil ha sido crítico de muchos programas de planificación familiar que reciben fondos del exterior. Algunos años atrás, el Consejo sobre la Situación de la Mujer del Estado de San Pablo evaluó a PRO-PATER entre otras agencias que practicaban esterilizaciones con fondos provenientes de los Estados Unidos. En su informe, el Consejo mostró preocupación sobre la posible variación en los criterios para aceptar candidatos para vasectomías, un posible flujo excesivo de clientes, parcialidad en la promoción de la esterilización, e insensibilidad a los problemas políticos relacionados con la ayuda del exterior. ${ }^{10}$ Aunque ninguno de estos asuntos ha llegado a ser un problema para PRO-PATER, de todos modos han resultado en que la clínica no gane la confianza del poderoso e influyente movimiento de salud femenina en el Brasil. Además, la decisión de PRO-PATER de no distribuir condones en un país que tiene uno de los más altos índices de casos de SIDA en el mundo, preocupa a Margarethe Arilha, una psicóloga y activista del movimiento de salud femenina que estuvo en la Comisión de San Pablo cuando se publicó el informe."

\section{La Clínica para el Hombre: un enfoque colombiano}

PRO-PATER ha estructurado su clínica y su imagen con una orientación casi exclusivamente masculina. Pero también pueden surgir exitosos programas para hombres a partir de programas de planificación familiar femeninos. Aunque este número de Quality/Calidad/ Qualité está dedicado principalmente a PROPATER, es conveniente mencionar también la experiencia de su prima colombiana, la Clínica para el Hombre.
PROFAMILIA es una de las mayores y mejor establecidas organizaciones de planificación familiar del mundo. Fundada en 1965, tiene en este momento 48 clínicas en Colombia. A principios de la década del 70 PROFAMILIA comenzó a practicar esterilizaciones. Por falta del equipo quirúrgico requerido para hacer esterilizaciones femeninas, la organización empezó a practicar vasectomías. Pero en 1973, cuando se adquirió el equipo necesario, el programa de vasectomías casi desapareció, a medida que el número de ligamientos de trompas aumentaba rápidamente. No fue hasta 1985 cuando, alentados por el éxito de PRO-PATER y con el apoyo de la AVSC, PROFAMILIA decidió recomenzar con un programa completo de vasectomías.

Ya en esta época, los dirigentes tenían una visión más amplia. La directora de la clínica para hombres, Cecilia Cadavid, quien ha estado con PROFAMILIA casi desde su comienzo, explica: "Decidí crear una clínica que podría ser diferente e integrar otros servicios, además de vasectomías. Ofrecemos análisis y tratamiento de problemas urológicos y sexuales, infertilidad y enfermedades de transmisión sexual. También ofrecemos exámenes médicos generales, condones, educación en planificación familiar, y, por supuesto, vasectomías".

Este nuevo enfoque fue pensado no sólo para responder a las necesidades de un grupo más amplio de clientes, sino también para ser económicamente estable. Dice Cecilia Cadavid: "Muchos hombres no pagarían por una vasectomía a menos que sea muy barata, porque no se piensa en ella como una necesidad urgente. Por otro lado, un hombre con ardor al orinar o con preocupaciones de índole sexual se siente más urgido por su problema, y está más predispuesto a buscar y pagar por los servicios. Por eso es que cobramos más por algunos servicios (particularmente en el laboratorio y la farmacia) para subsidiar las vasectomías. Por supuesto, como compramos muchos medicamentos y tenemos nuestro propio laboratorio, el cliente termina pagando menos de lo que pagaría en la actividad privada. Al mismo tiempo, ganamos un margen suficiente como para mantenernos a flote". Por ejemplo, la clínica para hombres en Bogotá tiene una ganancia mensual de US\$ 1.000 sólo en aranceles de laboratorio. Si estas ganancias disminuyeran, dice Cecilia Cadavid, 


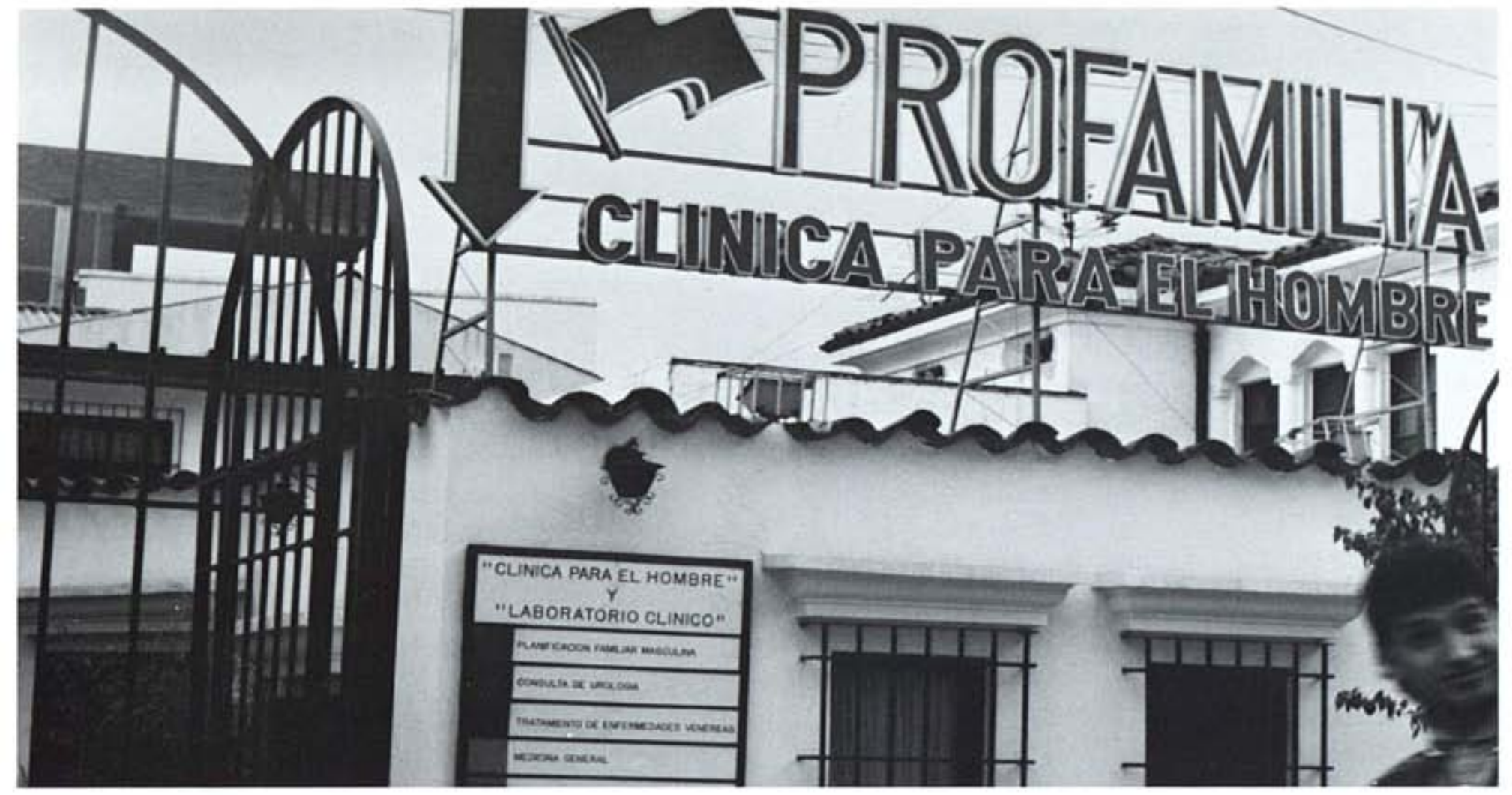

tendrían que reducir también el número de vasectomías que se ejecutan.

La otra parte del plan inicial fue que la Clínica para el Hombre debería contar en su inicio con el "equipo de mayor experiencia" de PROFAMILIA. Pero a pesar de un plan económico y de personal pensados para asegurar el éxito del programa, la clínica no tuvo un comienzo fácil.

En primer lugar, a los médicos de PROFAMILIA no les gustó que se pusiera a la cabeza de la clínica a alguien que no era médico. Segundo, desde que no existía el precedente de un centro para salud masculina reproductiva y sexual, recibieron una gran cantidad de llamados "pornográficos". Para empeorar las cosas, se cometió el error de emplear a algunas personas cuya conducta no fue la apropiada con los clientes. Por supuesto, dichos empleados fueron despedidos del programa.

Otro obstáculo fue establecer un flujo de clientes. Al comienzo había tan pocos, que el equipo decidió montar una campaña radial (después de eso la Clínica ha hecho también publicidad por televisión). Y pronto el equipo descubrió la necesidad de hacer que el edificio fuera atractivo y acogedor. "Aprendimos que la apariencia es más importante para los hombres que para las mujeres. Las mujeres están acostumbradas a venir a la clínica de planificación familiar. Los hombres nunca lo han estado, y su primera impresión se basa en gran parte en cómo se ve el lugar. De modo que pusimos un gran cartel en el frente y comenzamos a servir café. Todavía es difícil para los hombres cuando llegan por primera vez. Una vez que ya han venido les es fácil volver".

Cuando comenzó a aumentar la cantidad de clientes, el equipo notó que la gran mayoría pedían al llegar un examen físico. Es difícil imaginar cómo un hombre podría llegar a una nueva y extraña clínica, y decirle a la recepcionista que ha venido porque tiene problemas de erección o porque piensa que tiene sífilis. Comprensiblemente, muchos hombres decían que querían un examen físico; la preocupación verdadera sólo salía a la luz durante el examen. Obviamente, muchos de esos exámenes eran innecesarios, además de ser costosos. De modo que la clínica entrenó a enfermeros para entrevistar a cada cliente y determinar si debería ser derivado al laboratorio, al sexólogo, para una cita de vasectomía, etc. Aunque comenzaron usando sólo entrevistadores masculinos, la Clínica usa ahora enfermeros y enfermeras. Al igual que la experiencia de PRO-PATER y otros programas para hombres en los Estados Unidos, la Clínica ha encontrado que los hombres pueden hablar fácilmente con mujeres, si se les hace sentirse cómodos y ven 
Juan tiene 37 años. "Tengo cuatro hijos. Dos son mellizas de seis años de edad. Mi esposa usaba la píldora, pero la hacía engordar mucho. Fue entonces a un programa para adelgazar. Después le colocaron un dispositivo intrauterino, $y$ quedó embarazada. Seis meses o un año atrás, empezamos a pensar en que ella debía hacerse la esterilización. Pero sabemos que algunas mujeres se han enfermado mucho por esa causa. Entonces fue que escuchamos sobre la vasectomía en la radio.

"Yo nunca había oído de eso antes. Me dio miedo. ¿Qué podría llegar a pasar? ¿Qué podría pensar la gente? Sólo lo sabe mi esposa, y no pienso decírselo a nadie más. Los hombres somos también machistas...

"Lo que me gusta más de Profamilia es la atención, y que es voluntario y barato. Pago 2.000 pesos, y gano cerca de 80.000 pesos por mes. Me gustaría más si no hubiera tantas mujeres alrededor. Cada vez que camino por el pasillo, hay muchas mujeres mirándome... Ayer vine por vez primera. No vine antes porque habia muchas mujeres.

"Yo manejo un taxi. No conozco a ningún otro que tenga una vasectomía. Me sentí mejor porque habia aquí otro hombre con quien pude hablar y calmar mis nervios. Me hicieron la operación hoy [viernes] y creo que volveré el lunes al trabajo".

Después de haber afrontado problemas de resistencia cultural, de personal, y de escasez de clientes, Cecilia Cadavid dice que su mayor satisfacción está a la vista: después de sólo tres años, la Clínica para el Hombre es, por varias razones, un éxito rotundo.

En primer lugar, se autofinancia en el 92 por ciento. La clínica tiene ahora cinco sitios; además de Bogotá, también Medellín, Cali, Pereira y Cartagena. Posiblemente el hecho más notable es que la Clínica para el Hombre atiende un promedio de 750 nuevos clientes cada mes. 250 vienen por problemas urológicos, 190 por exámenes de enfermedades sexuales, 125 por vasectomías, 75 por problemas generales de salud, 55 por preocupaciones sexuales, 50 por infertilidad y un pequeño número por otros servicios. Además, cada mes la Clínica ve más de 500 hombres en visitas de segui- miento, y vende más de 2.000 condones. El equipo también da tratamiento a las parejas de los clientes con enfermedades sexuales o con problemas de infertilidad. El programa había estado ofreciendo el examen de sangre para detectar anticuerpos del SIDA, lo que dio origen al rumor de que la Clínica estaba dando tratamiento a personas con SIDA, y la clientela disminuyó. Así que la Clínica provee ahora solamente educación sobre el SIDA, y deriva los clientes a otra institución para el examen de sangre.

El enfoque que tiene PROFAMILIA de la disfunción sexual es similar al de PRO-PATER. Los problemas de naturaleza orgánica se tratan químicamente o con cirugía, pero la mayoría son enfocados como de origen psicológico. Se enfatiza la comunicación y el respeto como fundamentales para una relación sana. Aunque el doctor Alvaro Poveda, sexologista del programa, admite que en el principio pensó que la eyaculación prematura sería muy difícil de resolver, el programa combinado de consejería de corto plazo, relajación y técnicas conductistas ha tenido éxito en el 85 por ciento de los casos. Al preguntársele cuál es su satisfacción más grande, el doctor Poveda dice que es "encontrar que las mujeres que vienen con sus maridos comprenden mi enfoque; al principio me preocupaba eso también".

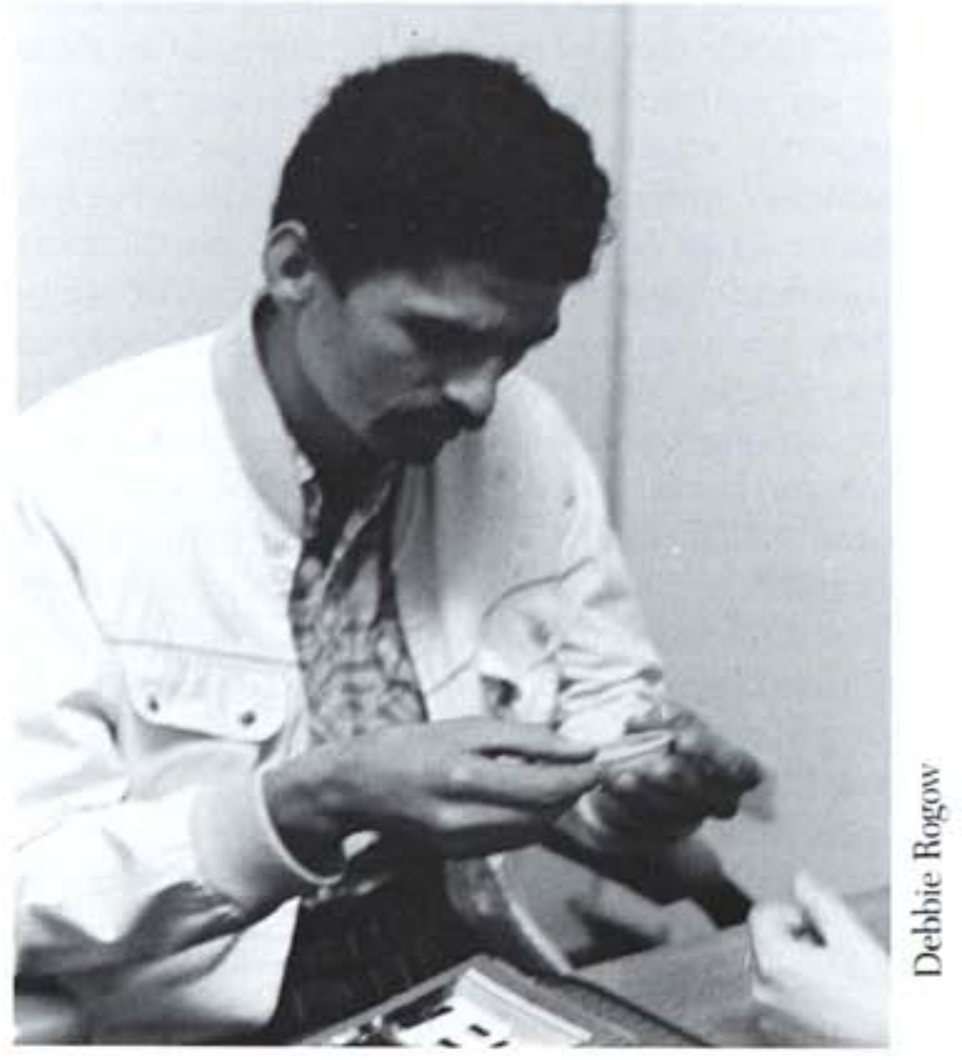


A pesar del éxito, el equipo de la Clínica no está todavía conforme. Cecilia Cadavid quisiera que el programa tenga su propio edificio, más grande y diferenciado del programa para las mujeres. Algunos de los clientes de vasectomía me dijeron que su única queja era que se sentían incómodos vistos en túnicas de cirugía desde la sala de espera. A Cadavid le gustaría también tener dinero para poner regularmente avisos en la televisión.

El doctor Alvaro Poveda, el sexologista de la clínica en Bogotá, desearía poder pasar más tiempo con cada cliente. "Veo uno cada veinte minutos. He tratado, pero ¿qué puedo hacer?” Efraín Poveda, uno de los enfermeros, repite el deseo de Cadavid de tener un edificio aparte, y dice que necesita mayor entrenamiento en sexualidad, para poder ayudar mejor a los clientes. Y Marta Castañeda, otra enfermera que también trabaja en difusión en la comunidad, quisiera que el programa proveyera más educación sexual a los hombres.

Desafiar ideas viejas no es fácil. Al igual que PRO-PATER, la Clínica para el Hombre ha superado enormes obstáculos para proveer una gama mayor de servicios de salud reproductiva y opciones anticonceptivas a los hombres colombianos. Hoy la Clínica sirve como un punto de entrenamiento para otras instituciones en Colombia y América Latina, y recibe visitantes de otros programas de planificación familiar de todo el mundo. La clave de su éxito es un estudio cuidadoso de lo que es más importante para los clientes: un lugar atractivo, atención individual, amplia gama de servicios, vasectomías de bajo costo, y abrir los sábados. Luego adquirieron el personal apropiado, adoptaron un plan económico de acuerdo con las necesidades de los clientes, hicieron correr la voz de que habían abierto, y mantuvieron la fe. Aunque hacer una evaluación final sería prematuro, PROFAMILIA cree firmemente que la aceptación por parte de los hombres de esta diversificada clínica para hombres solamente, es la mejor estrategia para atraer hombres a la planificación familiar $\mathrm{y}$, al mismo tiempo, generar recursos locales para que la clínica sea autosuficiente.

Ocho mil clientes después, Cecilia Cadavid tiene todavía en su escritorio, como un testimonio de esa fe, una fotografía ampliada del primer grupo de 24 clientes de vasectomía de la Clínica.

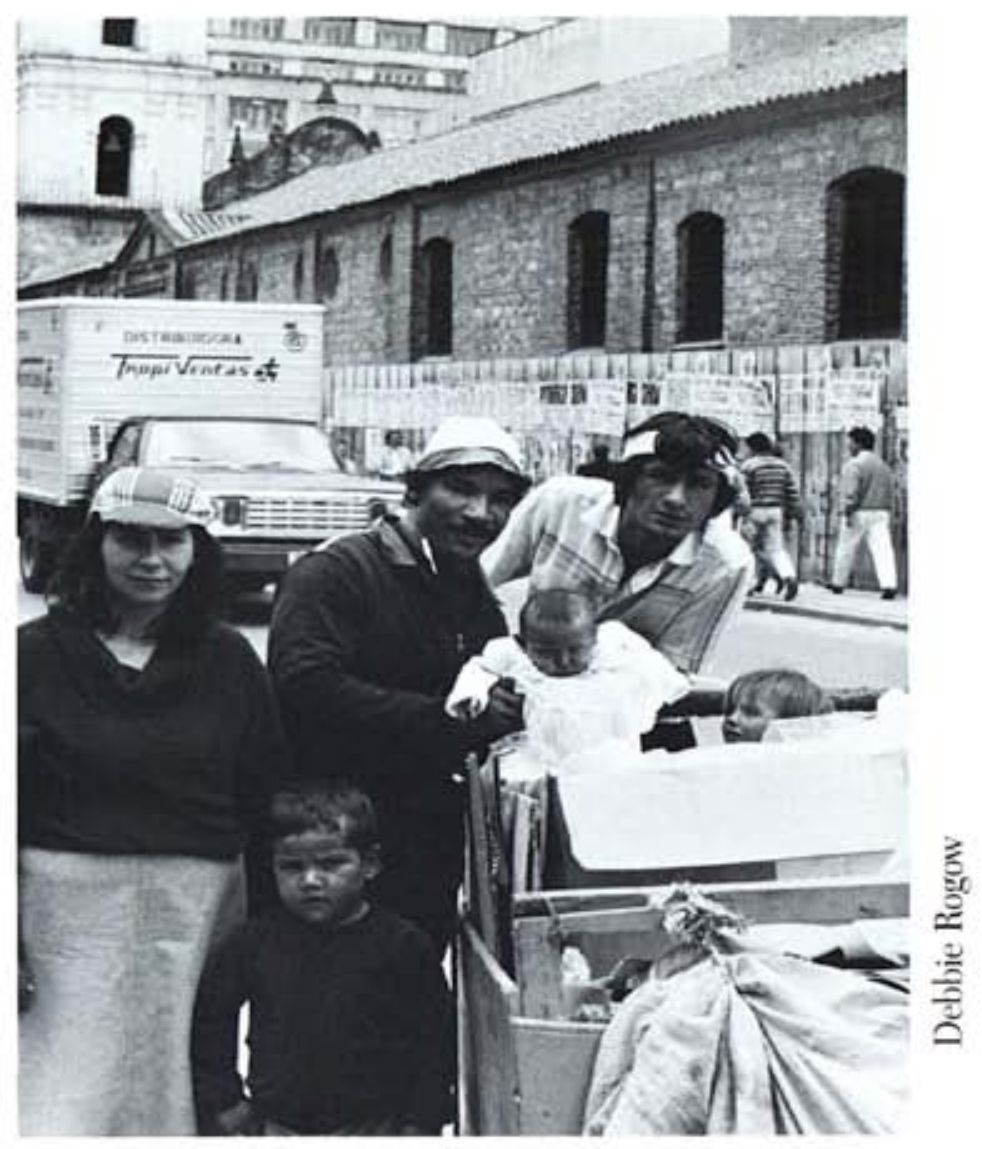




\section{Lo que se puede aprender}

De las experiencias de PRO-PATER y PROFAMILIA se pueden deducir algunas lecciones que son invalorables, no sólo para los que tienen interés en servicios para hombres, sino para todos los que en este campo nos interesamos en la creatividad y en el compromiso programático con la calidad.

1. Existe una clientela para servicios de salud reproductiva masculina integrados, y definir la salud masculina en forma más amplia hace que al hombre le sea más fácil llegar al lugar. Una vez que llega, cuando su ansiedad ha sido aliviada en cierta manera por el ambiente y la recepción que recibe, el hombre puede expresar con mayor libertad la real naturaleza de su visita (planificación familiar, impotencia, enfermedad sexual, infertilidad, etc.)

2. Si en los casos de esterilización se pone énfasis en el proceso de consentimiento informado, el resultado será menos casos de arrepentimiento o de pedido de reversión del procedimiento. PRO-PATER define la consejería como un desarrollo de consenso con un cliente en cuanto a si la esterilización es una buena solución, mencionando todas las razones por las cuales el cliente podría lamentar después su decisión, explorando el conocimiento y la experiencia que el cliente tiene con cada uno de los otros métodos de anticoncepción. PROPATER mide su éxito no por el número de vasectomías practicadas, sino por su bajo índice de complicaciones y la virtual ausencia de pedidos de reversión del procedimiento.

$\mathrm{Si}$ se le pregunta a Bernadette de Castro qué ha aprendido de la experiencia de PROPATER, su respuesta gira sobre la importancia de mantener un buen nivel de consejería y análisis de casos, atención individual, y tratamiento de cada persona como un ser humano, independientemente de su posición socioeconómica.

3. Los medios masivos de comunicación son una manera muy efectiva de informar a los hombres sobre la existencia de servicios de salud reproductiva masculina. Aunque PROPATER y PROFAMILIA usan una combinación de difusión de boca a boca y trabajadores comunitarios, han usado también con éxito los medios masivos para atraer clientes para vasectomía. La campaña de PRO-PATER con avisos en revistas fue cuidadosamente designada para alcanzar a un sector específico de la población, y promover una imagen positiva de la vasectomía. PROFAMILIA ha diseñado un aviso de treinta segundos para la televisión, y durante años ha dependido de la radio para atraer clientes.

4. Ofrecer servicios de buena calidad puede ayudar a un proyecto polémico a obtener legitimidad política. La mejor manera de enfrentar un clima político semihostil hacia un determinado proyecto es mejorarlo y hacerlo tan bien que eso sólo neutraliza la mayoría de la oposición. PRO-PATER y PROFAMILIA operan en un ambiente en que la Iglesia Católica dice que la esterilización es no sólo inmoral sino también ilegal, y proveen vasectomías en países donde la responsabilidad por el control de la natalidad descansa casi exclusivamente en la mujer. En Brasil, el movimiento feminista se opone a los programas de esterilización subvencionados por organizaciones de los Estados Unidos. Sin embargo, ambos programas han maniobrado para establecer una clientela grande, diversificada y satisfecha; han entrenado equipos de médicos, y han logrado espacio para un método en lugares donde antes fue poco conocido y fuera del alcance de la mayoría. 


\section{Conclusión}

El éxito de los programas de PRO-PATER y PROFAMILIA ofrece cierta guía en cuanto a cómo las clínicas deben estructurar los servicios comprensivos de salud reproductiva masculina.

En primer lugar, ambas clínicas tienen instalaciones separadas para hombres, de modo que estos no tengan que usar la misma entrada o salas de espera con otras mujeres que no sean su pareja. Sin embargo, aunque la clínica de PROFAMILIA tiene su propia entrada, salas de espera y de consejería, también comparte algunas zonas con la adyacente clínica para mujeres, y eso crea momentos de incomodidad para algunos hombres si se encuentran con mujeres mientras están utilizando los servicios. Esto es una indicación de cuán importante es dar al hombre el ámbito privado que él desea. Por otro lado, también está el aparentemente contradictorio hallazgo de PROFAMILIA y de las clínicas de hombres en los Estados Unidos: los hombres están igualmente dispuestos a recibir consejería de un hombre o una mujer, siempre que sientan que se está respetando su necesidad de confidencialidad.

Otro elemento clave en el éxito de estos programas es su énfasis en una consejería comprensiva, no sólo en relación con la vasectomía, sino también cuando se trata de preocupaciones sobre sexualidad. El alto índice de rechazo de candidatos para vasectomías en PRO-PATER puede ser un indicio de la calidad de su consejería. Esto sugiere que un servicio de vasectomías que no rechaza clientes con regularidad está proveyendo consejería inadecuada.

Aunque el énfasis de PRO-PATER y de la Clínica para el Hombre es en vasectomías, ambos incluyen ahora servicios adicionales de salud reproductiva para hombres. Las razones son claras: la amplitud de servicios es esencial si un programa realmente intenta ofrecer servicios multifacéticos, y no solamente practicar procedimientos de esterilización. Además, estos servicios complementarios pueden generar ingresos adicionales para sostener los programas de vasectomías, que frecuentemente operan en déficit en los países en vías de desarrollo. Si en algún momento los programas de planificación familiar van a llegar a autofinanciarse, y al mismo tiempo continuar manteniendo sus servicios al alcance de las personas de bajos ingresos, será necesario que los programas que producen ganancia ayuden a los componentes que no pueden ser ofrecidos a la mayoría de los clientes a su costo real. En los Estados Unidos, algunas clínicas de planificación familiar usan el ingreso producido por tratamientos (tales como terminación de embarazos) para financiar otros servicios de salud preventiva de gran necesidad pero para los cuales es difícil encontrar fondos, tales como consejería gratuita de planificación familiar y servicios para adolescentes que no tienen ingresos propios.

Hay diferencia entre los dos programas, en cuanto a la combinación de servicios que ofrecen. PRO-PATER y PROFAMILIA han agregado consejería de problemas sexuales y servicios de infertilidad, y proveen tratamientos para problemas masculinos. Aunque PROPATER trata enfermedades sexuales, con la excepción del SIDA, no publicita este servicio ni distribuye condones. PROFAMILIA hace los análisis por enfermedades sexuales y distribuye condones, y también ofrece exámenes médicos generales. Es indudablemente polémica la decisión de PRO-PATER de no distribuir condones, ni siquiera entre sus clientes después de practicar la vasectomía. Por el momento su explicación es que a la mayoría de los clientes de vasectomías no les gustan los condones, y que sus parejas están por lo general usando un método de planificación familiar. Hay también una preocupación por mantener la excelente reputación profesional de la clínica en un clima político y social que todavía es sensible. Sin embargo, en la medida en que se preste mayor atención al incremento en el Brasil de los índices de infección con el virus de inmunodeficiencia humana (HIV) y las enfermedades de transmisión sexual, cambiará posiblemente la actitud de la población y los líderes en cuanto a la importancia del uso del condón.

\section{La expansión del conocimiento de la salud reproductiva y el acceso a los servicios}

Los programas de planificación familiar han explotado tres formas básicas para la distribución de anticonceptivos: servicios clínicos, mercadeo comercial y distribución comunita- 
ria. Consideremos brevemente las posibilidades de cada uno de estos tres enfoques en relación a su efectividad en responder a las necesidades masculinas, y luego analicemos la posibilidad de expandir el conocimiento de los hombres sobre su propia salud reproductiva y el acceso a la tecnología de salud y tratamiento.

El éxito de PRO-PATER y de la Clínica para el Hombre demuestra que un enfoque basado en una clínica puede ser exitoso en alcanzar a los hombres. Sin embargo, no todos los programas tienen los recursos disponibles para establecer una estructura separada para servir a los hombres. Una posible alternativa sería ofrecer servicios para hombres en ciertos días de la semana, días en que no se atenderá a mujeres, y establecer horarios específicos, tales como las primeras horas de la mañana u horarios por la tarde. La experiencia de clínicas en los Estados Unidos indica que este enfoque puede funcionar, pero el ambiente de la clínica debe transformarse de un espacio femenino en un espacio masculino, de modo que los hombres se sientan a gusto. Para mantener la separación, se debe advertir a hombres y mujeres que respeten estrictamente el horario de la clínica. Se pueden alentar también otros experimentos que aunque no signifiquen una separación física total puedan preservar la privacidad de los hombres. En todos los casos, para servir exitosamente a la clientela masculina, el personal debe recibir entrenamiento especial.

Mirando desde otro ángulo, todavía debe trabajarse en un enfoque de "pareja" para la planificación familiar, incluso para la mayoría de los servicios de infertilidad $y$ sexualidad. Muchas clínicas de mujeres invitan al hombre a acompañar a su pareja, pero a los hombres que llegan se los ve frecuentemente incómodos en la sala de espera o esperando afuera. Y los programas para hombres han sido exclusivistas en la misma manera. Posiblemente la única excepción a este énfasis en la separación por sexos sea la de los programas que proponen la "planificación familiar natural", que son generalmente manejados por iglesias. Aunque muchos clientes, hombres y mujeres, prefieren indudablemente un ambiente clínico orientado hacia su propio sexo, los programas de planificación familiar interesados en servir a la "pareja como pareja" debieran mirar a los programas que enseñan abstinencia periódica en busca de detalles imitables que podrían adaptarse a los lugares que enseñan sobre una variedad de métodos.

\section{Mercadeo social y comercial de anticonceptivos}

Al considerar formas de alentar mayor participación masculina en la planificación familiar, lo importante es que para los hombres que no están listos todavía para terminar su fertilidad, existe sólo otra opción: los condones. Los condones fueron un recurso grandemente ignorado durante años, hasta que los programas de mercadeo social y distribución comunitaria vieron que su seguridad, bajo costo y facilidad de uso, los hacía apropiados para distribución fuera de los canales médicos.

En muchos proyectos del sector comercial en América Latina, la mayoría de los condones se venden todavía en las farmacias. Expandiendo el número de lugares de venta, incluyendo otro tipo de comercios, barberías, $\mathrm{e}$ incluso vendedores callejeros (que son una gran parte de la economía informal de la región), los condones estarían a disposición de una clientela mucho más amplia. Además, los condones deberían ser comercializados más abiertamente. En la mayoría de los lugares, se los mantiene fuera de la vista, detrás del mostrador, obligando al comprador potencial a pedirlos. La investigación en México ha demostrado que las ventas son mayores y que más hombres los compran cuando los condones están exhibidos en lugares de fácil acceso, de modo que se pueda tomarlos sin necesidad de preguntar por ellos. Por lo demás, los hombres no saben automáticamente cómo usar los condones, y en la mayoría de los casos, son demasiado orgullosos como para preguntar. Por ello, se deberían incluir instrucciones gráficas, claras y fáciles de entender, dentro o fuera del paquete.

\section{Distribución comunitaria}

Muchos programas de distribución comunitaria se han enfocado en mujeres y usan promotoras mujeres. Esto ha limitado la participación masculina. Con una pequeña reestructuración, y usando hombres, los programas de distribución comunitaria podrían aumentar la distribución de condones. Aunque la experiencia en América Latina indica que es más difícil reclutar distribuidores masculinos (posible- 


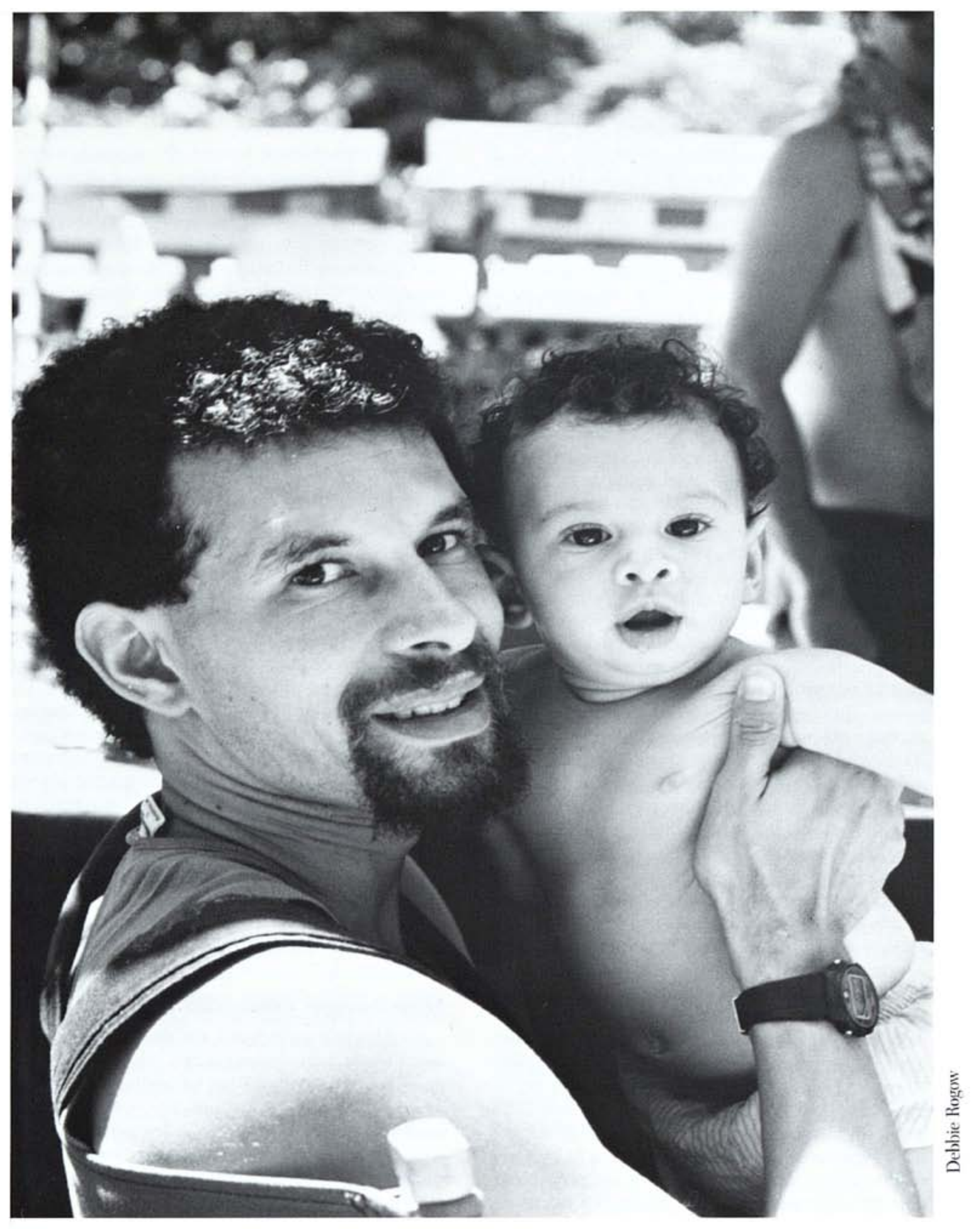


mente debido sólo a falta de experiencia), una vez que han sido reclutados los hombres distribuyen tanto como las mujeres, pero los clientes y métodos reflejan el sexo del promotor: los hombres distribuyen más condones y las mujeres, más píldoras. Los distribuidores masculinos pueden ser usados también para informar a otros hombres sobre servicios de vasectomía.

\section{Aumento del conocimiento masculino}

Los medios de comunicación pueden aumentar el conocimiento y la comprensión de métodos masculinos, estimular el interés y las preguntas, y, en el caso de la vasectomía, comenzar a crear un clima de aceptación para lo que es frecuentemente una opción de planificación familiar poco conocida o comprendida. Reflexionando sobre el éxito de la campaña de PRO-PATER en revistas, José Carlos Pires, que diseñó la campaña, enfatiza que "en lugar de comprar un producto, la campaña invitaba al cliente a considerar la posibilidad de la vasectomía, aprender más sobre ella y visitar PROPATER o a su médico particular para tener más información".

Una evaluación reveló que los nuevos clientes que llegaron a la clínica como resultado de la campaña publicitaria tenían menos conocimiento de la vasectomía, que los clientes que habían sido derivados por medios tradicionales, tales como hombres que ya habían tenido una vasectomía. Estos nuevos clientes también estaban más interesados en recibir información sobre el procedimiento que en hacer una cita para someterse a la vasectomía; esto probablemente fue porque habían tenido menos oportunidad de pensar sobre el procedimiento y discutirlo con otros clientes de la clínica, familiares o amigos. Cuando estos clientes decidieron tener una vasectomía, también esperaron más para determinar una fecha para hacerla. ${ }^{12}$

PROFAMILIA ha hecho también uso de los medios de comunicación para promover sus servicios de vasectomía. Al principio, la prensa pensó que la existencia de clínicas para hombres, y especialmente clínicas para vasectomías, era una cosa novedosa, de modo que aparecieron numerosos reportajes en la prensa, la radio y la televisión. Cuando el interés inicial se desvaneció, PROFAMILIA contrató una agencia de relaciones públicas para que organizara reuniones con los periodistas. En la experiencia de PROFAMILIA, la radio y la televisión han sido los mejores medios de informar al público sobre los servicios ofrecidos por las clínicas para hombres, especialmente entrevistas durante programas médicos y de opinión. Las revistas, periódicos y otras publicaciones escritas tienden a ser el material de lectura de una audiencia mejor educada que la mayoría de los clientes que llega a la clínica. PROFAMILIA también probó el uso de publicidad con grandes carteles, pero esto no produjo ningún resultado.

Por el momento, si se quiere incrementar el uso de anticonceptivos masculinos, los dos métodos actualmente disponibles deben hacerse más accesibles a los hombres. Esto puede lograrse incrementando la aceptación general de estos métodos, mejorando el acceso a ellos, y poniendo un mayor énfasis en la calidad del servicio que se brinda. Sin embargo, es esencial que en el futuro se desarrollen nuevas opciones para los hombres, ya sea mejores condones o enfoques y sistemas totalmente nuevos. El problema y el desafio está, más que en la falta de demanda, en el suministro y tecnología apropiados. 


\section{Notas}

1. Meredith, Philip. Male Involvement in Planned Parenthood: Global Review and Strategies for Programme Development. (Londres: IPPF, 1989.)

2. Germain, Adrienne. "Reproductive Health and Dignity: Choices by Third World Women." En Abstracts: The Key Findings of 13 Technical Background Papers de la Conferencia para el Mejoramiento de la Salud Materna e Infantil con la Planificación Familiar, Nairobi, Kenia, 5 al 9 de octubre, 1987. (New York: The Population Council, 1987.)

3. Forrest, Katherine A., Janice M. Swanson and Douglas E. Beckstein. "The Availability of Educational and Training Materials on Men's Reproductive Health." Family Planning Perspectives, v.21, n.3, mayo/ junio 1989.

4. (IPPF) People, "Motivating Men" (editorial), v.13, n.1, 1986.

5. Arruda, J.M. et al, "Pesquisa Nacional Sobre Sáude Materno-Infantil e Planejamento Familiar," PNS-MIPS, Brasil, 1986. (Rio de Janeiro, Brasil: BEMFAM y I.R.D., Westinghouse, diciembre 1987.)

6. Pinotti, J.A., et al, "Identifição de Fatores Asso- ciados a Insatisfaçāo após Esterilizaçâo Cirúrgica," Ginecol.-Obstetricia v.9 n.4, p.304, 1986.

7. Annon, Jack S., The Behavioral Treatment of Sexual Problems, Vol.I, Brief Therapy, Rev: Ed. (Enabling Systems, Inc., 1976.)

8. De Castro M.P.P., et al, "Pesquisa Pro-Pater: Nível de Informaçāo, Uso, Aconselhamento, e Prática de Planejamento Familiar por Médicos de São Paulo, Brasil:" (São Paulo, Brasil: PRO-PATER, octubre 1986.)

9. Foreit, Karen G., Marcos Paulo P. de Castro, and Elaine F. Duarte Franco, "The Impact of Mass Media Advertising on a Voluntary Sterilization Program in Brazil," Studies in Family Planning, v.20, n.2, March/ April 1989.

10. Arilha M.M., P. Goldenberg, S. Sorrentino, "Clínicas de esterilizaçâo: A quem servem?", Cadernos, n.2, (São Paulo, Brasil: Conselho Estadual da Condição Feminina, 1986.)

11. Arilha, M.M. Comunicación personal, septiembre de 1988.

12. Foreit, Karen G., citada en el no. 9 anterior. 


\section{Sobre las autoras}

Debbie Rogow es una consultora internacional sobre la salud reproductiva de la mujer, cuya experiencia previa incluye haber ayudado a establecer una clínica de salud reproductiva para varones en los Estados Unidos.

Judith Bruce es una Senior Associate del Population Council con un interés particular en temas relativos a la calidad de atención. Ann Leonard es una consultora en comunicaciones que trabaja primordialmente en los ámbitos de salud, planificación familiar y asuntos de la mujer; también es editora de Quality/Calidad/Qualité. Ambas desean agradecer al Dr. James Foreit por haber compartido sus conocimientos y sus atentos comentarios sobre la entrega de servicios de anticoncepción en América Latina.

\section{Comité asesor de Quality/Calidad/Qualité}

George Brown

Judith Bruce

Ethel Churchhill

Francine Coeytaux

Adrienne Germain

Ann Leonard

Margaret McEvoy

John Paxman
Debbie Rogow

Jill Sheffield

Lindsay Stewart

Kerstin Trone

Nahid Toubia

Beverly Winikoff

Margot Zimmerman $\begin{array}{ll}\text { Diseño: } & \text { Ann Leonard } \\ \text { Foto de tapa: } & \text { Debbie Rogow } \\ \text { Tipografia: } & \text { Village Type \& Graphics } \\ \text { Impresión: } & \text { Graphic Impressions }\end{array}$

Solicitamos sus comentarios e ideas sobre proyectos que podrían ser incluidos en futuras ediciones de Quality/Calidad/Qualité. Si desea recibir ejemplares adicionales de esta edición o quisiera ser incluido en nuestra lista postal, favor de escribir a: Ann Leonard, Editor, Quality/Calidad/Qualité, The Population Council, One Dag Hammarskjold Plaza, New York, N.Y. 10017 U.S.A. 


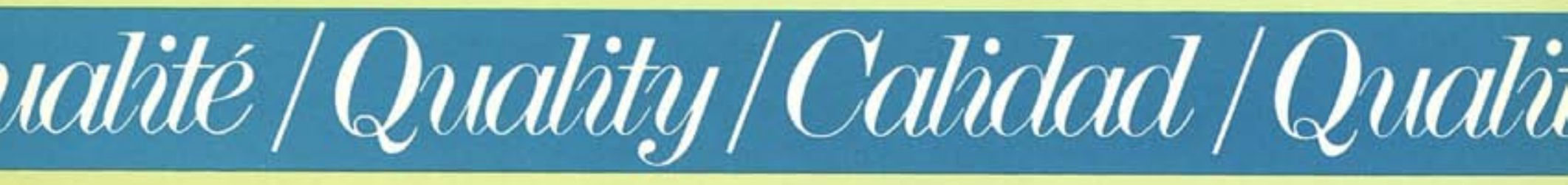

